\title{
Hearing in two tropical butterflies, Morpho peleides and Caligo eurilochus (Nymphalidae: Satyrinae)
}

\author{
By
}

Kathleen M. Lucas

\begin{abstract}
A dissertation
submitted to the Faculty of Graduate Studies and Research in partial fulfillment of the requirements for the degree of Master of Science in Biology

Carleton University

Ottawa, Ontario
\end{abstract}

(C) 2008 Kathleen M. Lucas 


$\begin{array}{ll}\begin{array}{l}\text { Library and } \\ \text { Archives Canada }\end{array} & \begin{array}{l}\text { Bibliothèque et } \\ \text { Archives Canada }\end{array} \\ \begin{array}{l}\text { Published Heritage } \\ \text { Branch }\end{array} & \begin{array}{l}\text { Direction du } \\ \text { Patrimoine de l'édition }\end{array} \\ \begin{array}{l}\text { 395 Wellington Street } \\ \text { Ottawa ON K1A 0N4 } \\ \text { Canada }\end{array} & \begin{array}{l}\text { 395, rue Wellington } \\ \text { Ottawa ON K1A 0N4 } \\ \text { Canada }\end{array}\end{array}$

Your file Votre référence ISBN: 978-0-494-44132-9

Our file Notre référence

ISBN: 978-0-494-44132-9

NOTICE:

The author has granted a nonexclusive license allowing Library and Archives Canada to reproduce, publish, archive, preserve, conserve, communicate to the public by telecommunication or on the Internet, loan, distribute and sell theses worldwide, for commercial or noncommercial purposes, in microform, paper, electronic and/or any other formats.

The author retains copyright ownership and moral rights in this thesis. Neither the thesis nor substantial extracts from it may be printed or otherwise reproduced without the author's permission.
AVIS:

L'auteur a accordé une licence non exclusive permettant à la Bibliothèque et Archives Canada de reproduire, publier, archiver, sauvegarder, conserver, transmettre au public par télécommunication ou par l'Internet, prêter, distribuer et vendre des thèses partout dans le monde, à des fins commerciales ou autres, sur support microforme, papier, électronique et/ou autres formats.

L'auteur conserve la propriété du droit d'auteur et des droits moraux qui protège cette thèse. $\mathrm{Ni}$ la thèse ni des extraits substantiels de celle-ci ne doivent être imprimés ou autrement reproduits sans son autorisation.
In compliance with the Canadian Privacy Act some supporting forms may have been removed from this thesis.

While these forms may be included in the document page count, their removal does not represent any loss of content from the thesis.
Conformément à la loi canadienne sur la protection de la vie privée, quelques formulaires secondaires ont été enlevés de cette thèse.

Bien que ces formulaires aient inclus dans la pagination, il n'y aura aucun contenu manquant.

\section{Canada}




\begin{abstract}
Many butterflies of the family Nymphalidae possess a sensory structure (Vogel's organ) that has been proposed to function in hearing. The function of this ear in diurnal, mute butterflies remains unknown, though it is hypothesized that they listen to the flight sounds of birds. I studied the functional significance of Vogel's organ in two tropical butterflies, Morpho peleides and Caligo eurilochus. First, I investigated the vibrational properties of the inner and outer membranes in M. peleides. These two regions displayed different vibrational properties, which potentially allow $M$. peleides to distinguish between two frequency ranges. Secondly, I tested the hypothesis that butterflies use their hearing to detect the flight sounds produced by predatory birds by comparing the diurnal M. peleides ear with that of the crepuscular C. eurilochus, and determined that its degenerate form may be due to the absence of avian predators.
\end{abstract}




\section{Acknowledgments}

I would like to thank my committee members Dr. John Lewis and Dr. Jeff Dawson for their input and recommendations during my Master's thesis. Special thanks go to my supervisor, Dr. Jayne Yack, for her unending support throughout two years of research and the preparation of this thesis. I can't tell you how much I appreciate Dr. Yack never turning me away at her office door to answer my never-ending barrage of questions, no matter how busy she was. I thank you for teaching me so much, and instilling in me a love of research in insect bioacoustics, despite the fact I still remain a bit squeamish around some creepy crawlies.

I'd like to thank the past and present members of the Yack lab for their support and friendship over the past two years. Shannon Mahony and Karla Lane provided the foundation of the butterfly research that I built upon in the Yack Lab and were a big help as I started my project. For help with neurophysiology, thank you Jenn Mongrain for keeping me company all those hours in the basement. To Jackie Bowen, A.J. Fleming, and Veronica Bura, thank you for being friends from the start and making my time in the lab so much fun. I would also like to thank members of the Carleton Biology Department: Dr. Jeff Dawson for all the advice and bioacoustics support, Dr. Sue Bertram for teaching me to think critically, and Ed Bruggink for his expertise and help with rearing the butterflies. For the collaborative work performed at the University of Bristol, I would like to thank Dr. Daniel Robert for graciously accepting me into his lab for three weeks, and to Dr. James Windmill for his patience in guiding me through the laser vibrometry work. And thank you to my family and friends, whose enduring love and support helped get me through grad school. 
Funding for this study was provided to Dr. J. E. Yack by the Natural Sciences and Engineering Research Council (NSERC) and the Canadian Foundation for Innovation (CFI). Funding to K. Lucas was provided by Carleton University, the Hibiscus Millennium Foundation, and the Journal of Experimental Biology (Travelling Fellowship). 


\section{Table of Contents}

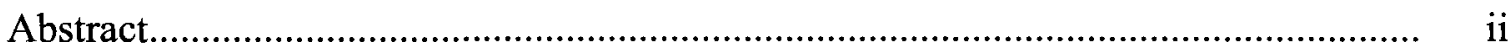

Acknowledgements...............................................................................................

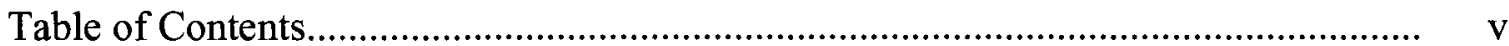

List of Figures.................................................................................................. vi

1. General Introduction....................................................................................

1.1 Hearing in Butterflies................................................................................ 3

1.2 Thesis Objectives................................................................................... 9

2. The functional significance of the tympanal membrane and associated chordotonal organs in the novel hearing organ of the tropical butterfly Morpho peleides (Papilionoidea, Nymphalidae) .................................................................. 12

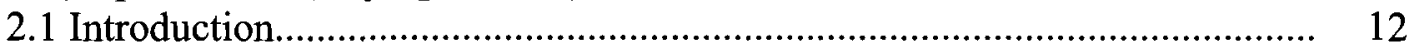

2.2 Materials and Methods.......................................................................... 16

2.2.1 Animals.......................................................................... 16

2.2.2 Histology ............................................................................ 16

2.2.3 Laser vibrometry ................................................................... 17

2.2.4 Neurophysiology................................................................... 19

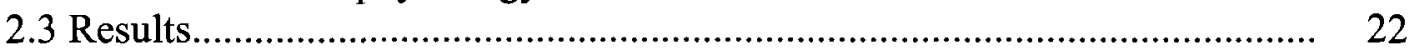

2.3.1 Morphology ....................................................................... 22

2.3.2 Vibrational analyses............................................................... 26

2.3.3 Neurophysiology ................................................................ 28

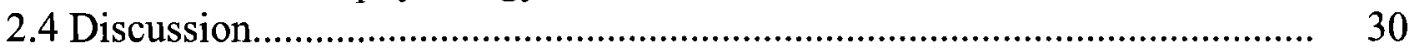

3. Hearing in the Owl butterfly Caligo eurilochus (Papilionoidea, Nymphalidae) 37

3.1 Introduction..................................................................................... 37

3.2 Materials and Methods...................................................................... 41

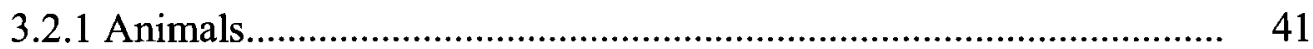

3.2.2 External morphology of Vogel's organ.......................................... $\quad 42$

3.2.3 Neurophysiology.......................................................................... 42

3.2.4 Laser vibrometry...................................................................... 44

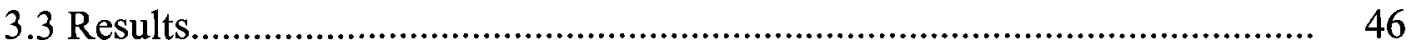

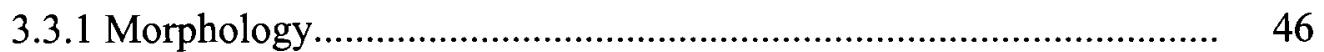

3.3.2 Neurophysiology ..................................................................... 49

3.3.3 Laser vibrometry........................................................................ 52

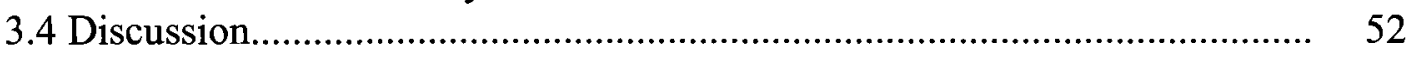

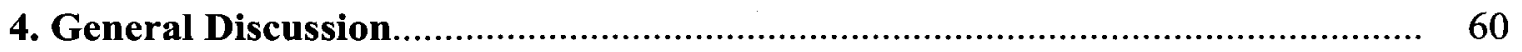

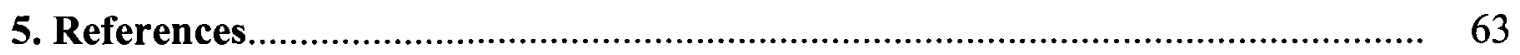




\section{List of Figures}

1.1 Phylogeny of the Lepidoptera................................................................. 2

1.2 Phylogenetic relationships of the butterflies .............................................. 4

1.3 The Vogel's organs of Morpho peleides and Caligo eurilochus...................... 8

2.1 Location and external morphology of the Vogel's organ in the butterfly Morpho peleides.

2.2 Schematic illustration of the innervation pattern of Vogel's organ in Morpho peledies.

2.3 Histological serial sections through Vogel's organ in Morpho peleides.

2.4 Histological sections of the three chordotonal organs in the Morpho peleides Vogel's organ.

2.5 Overall vibrational response of the Morpho peleides tympanal membrane.

2.6 Specific vibrational response of the Morpho peleides tympanal membrane: attachment points and transect.

2.7 Audiograms from extracellular nerve recordings of N.II in Morpho peleides..

3.1 Phylogeny of the butterfly subfamily Satyrinae, with representative Vogel's organs from Caligo eurilochus and Morpho peleides.

3.2 Location and external morphology of the Vogel's organ in the butterfly Caligo eurilochus.....

3.3 Scanning electron micrographs of the Caligo eurilochus Vogel's organ..........

3.4 Sensory responses to sound stimuli from extracellular nerve recordings from N.II and/or N.III in Caligo eurilochus.

3.5 Audiograms from extracellular nerve recordings of N.II and/or N.III in Caligo eurilochus.

3.6 Overall vibrational response of the Caligo eurilochus tympanal membrane....

3.7 The amplitude gain response of the Caligo eurilochus membrane to sound frequencies between $1-30 \mathrm{kHz}$. 
3.8 The deflection envelope of the tympanal membrane along a transect in Caligo eurilochus..

3.9 Comparison of the average auditory thresholds in Caligo eurilochus and Morpho peleides. 


\section{Chapter 1.}

\section{General Introduction}

Organisms sense the world in different ways, using visual, chemical, and auditory cues to better survive in a constantly changing environment. By understanding these cues, we are provided with invaluable insight into the ecology of these species with applications to animal behaviour, evolutionary ecology and conservation biology. Butterflies are a significant study species in the realm of sensory biology, and have been examined with respect to their visual and chemical sensory system. They are known to have a keen sense of vision that allows them to distinguish their host plant, recognize conspecifics, as well as orient themselves during both flight and rest (Warrant et al., 2003). Their chemical sense is also important, where chemical cues play a significant role in plant selection and detection of pheromones (Hallberg and Poppy, 2003). Interestingly, little attention has been paid to a possible sense of hearing in butterflies, even though a potential hearing organ was first described almost 100 years ago (Vogel, 1912), and a sense of hearing has been well studied in the closely related moths (Minet and Surlykke, 2003).

The order Lepidoptera is made up of 46 superfamilies (Kristensen and Skalski 1999) (Fig. 1.1). Hearing has been well studied in the Lepidoptera, but has focused mainly on the moths, which make up 43 superfamilies. Moth ears have been described by their evolutionary history, where ears have been shown to have evolved independently at least six times in response to predation pressure from insectivorous bats (Minet and 


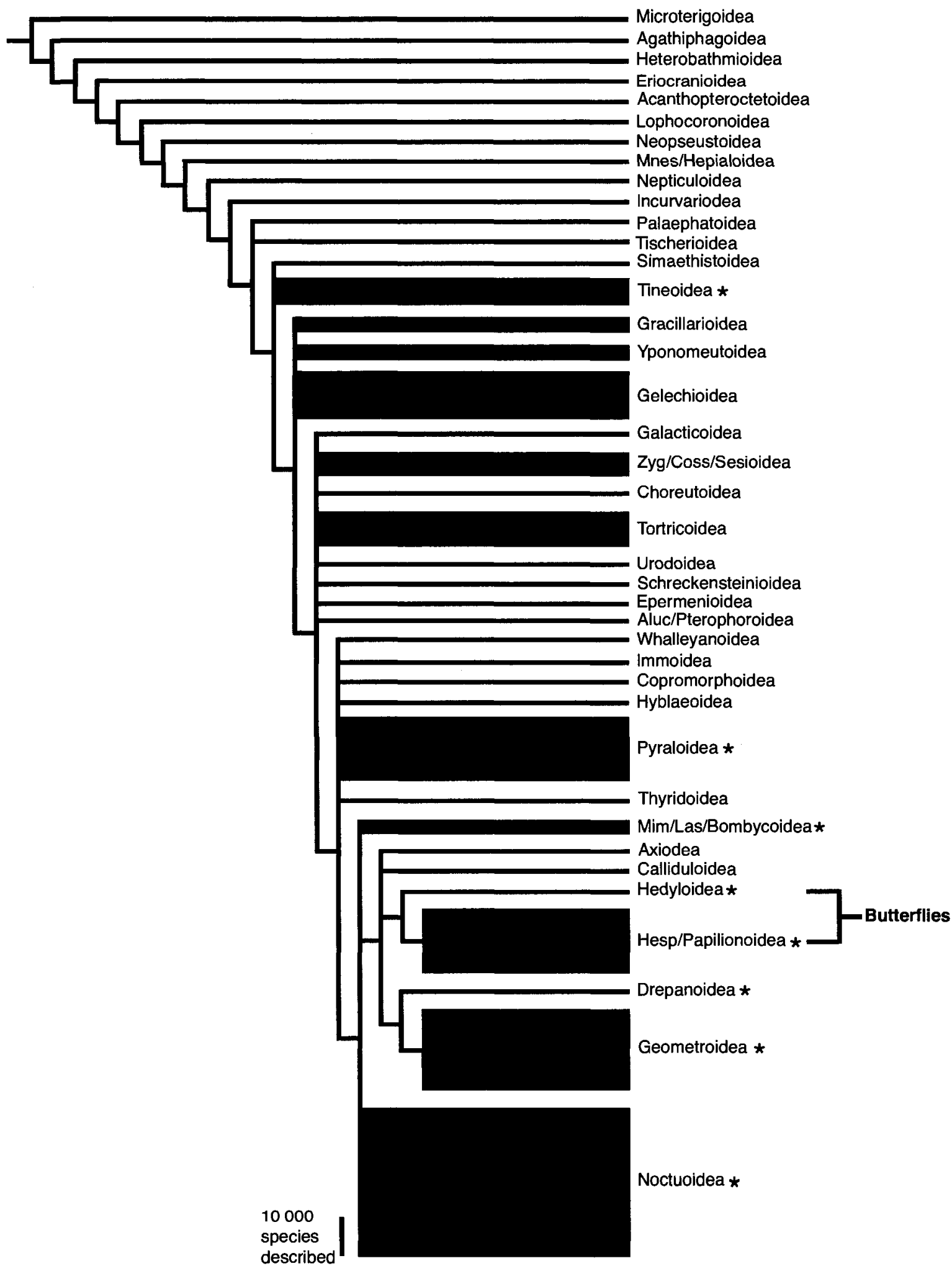

Figure 1.1. A phylogeny of the order Lepidoptera. The presence of hearing organs in a superfamily is denoted with an asterisk (*). Phylogeny adapted from Kristensen and Skalski (1999). 
Surlykke, 2003; Yack and Hoy, 2004). These ears detect high frequency sound corresponding to the echolocation calls of the bat (Minet and Surlykke, 2003). The point at which these ears evolved corresponds to the Eocene period 60 million years ago, which is when bats also evolved to echolocate (Novacek, 1985; Yack and Fullard, 2000). It is hypothesized that this predation pressure also led to the evolution of the butterflies, which saw a shift from a nocturnal to a diurnal lifestyle (Yack and Fullard, 2000). With respect to hearing in butterflies, one might expect these Lepidoptera to either (1) lack hearing, assuming a non-eared moth ancestor (2) have degenerate hearing in which the ancestral state was eared and is no longer useful to the diurnal butterflies, or (3) use hearing for other purposes than detecting bats.

\subsection{Hearing in Butterflies}

Butterflies form a monophyletic group of three of the Lepidopteran superfamilies: the Hedyloidea (neotropical nocturnal butterflies), the Hesperoidea (skippers), and the Papilionoidea (the 'true' butterflies) (Ackery et al., 1999) (Fig. 1.2A). Interestingly the Hedyloidea are thought to represent the ancestral form of butterflies as the link between moths and butterflies (Scoble and Aiello, 1990; Yack and Fullard, 2000). The hedylids are known to have a functional hearing organ at the base of the forewing that responds to the ultrasonic calls of insectivorous bats and mediates evasive flight maneuvers (Yack and Fullard, 2000; Yack et al., 2007). While it is not known whether the Hesperoidea possess aural capabilities, there is increasing evidence that they are pronounced in one family of the Papilionoidea, the Nymphalidae (Vogel, 1912; Otero, 1990; Mahony, 2006; King, 2007). Nymphalidae is one of the largest butterfly families with approximately 


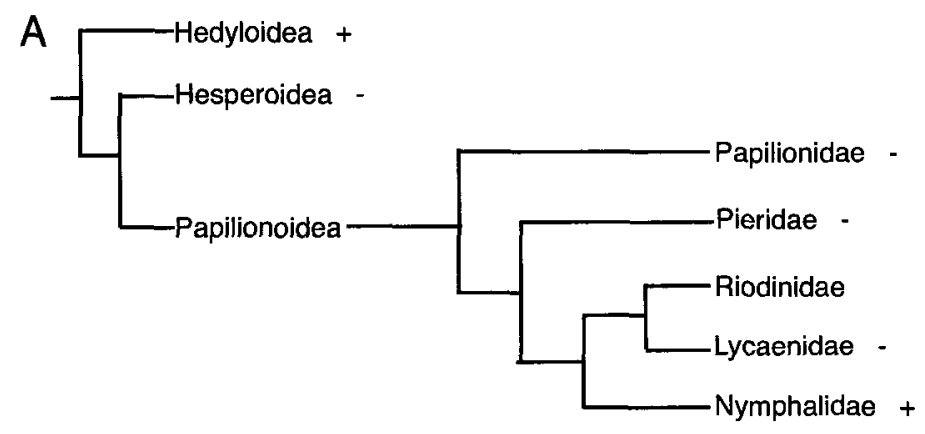

B

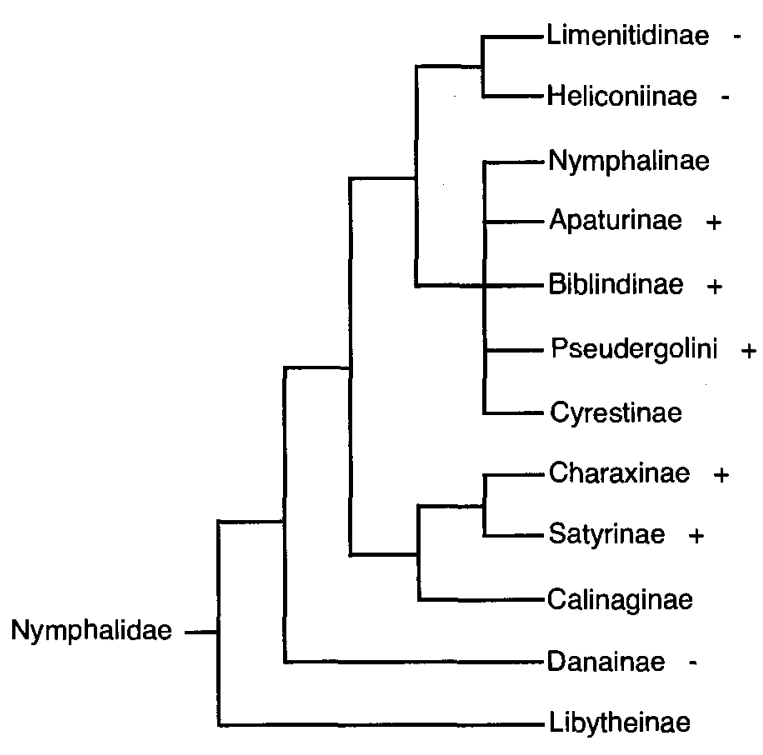

Figure 1.2. Phylogenetic relationships of butterfly groups showing where Vogel's organs have been noted in at least one species. A plus $(+)$ or minus $(-)$ sign indicates the presence of absence of a Vogel's organ, and groups that are unmarked represent those for which we did not have information. (A) Phylogenetic relationship of the butterfly superfamilies Hedyloidea, Herperoidea, and Papilionoidea (based on Kristensen and Skalski, 1999), and the families contained within the Papilionoidea (based on Ackery et al., 1999; Wahlberg et al., 2005). (B) Phylogenetic relationship of the Nymphalidae subfamilies (based on Ackery et al., 1999; Brower, 2000; Freitas and Brown, 2004; Wahlberg et al., 2003). Evidence for the presence or absence of a potential hearing organ were based on the following sources: Hedyloidea (Scoble, 1986; Yack et al., 2007); Hesperoidea (Otero, unpubl.); Papilionoidea (Otero, unpubl.); Lycaenidae (Robbins, pers. commun.); Pieridae (Otero, unpubl.); Limenitidinae (Otero, 1990); Apaturinae (Otero, 1990); Biblinidae (Otero, 1990 [cited as Eurytelinae]; Yack et al., 2000; Le Cerf, 1926); Charaxinae (Otero, 1990); Pseudergolini (Le Cerf, 1926); Satyrinae (Vogel, 1912; Mahony, 2006). Adapted from Lane et al. (2008). 
6000 species presently described (Ackery et al., 1999). A potential hearing structure was first described in 1912 and called the Vogel's organ (VO) (Vogel, 1912). It is characterized by a membranous structure located at the base of the cubital vein of the forewing associated with tracheal air sacs and chordotonal organs (Vogel, 1912). Subsequent descriptions of the VO have noted that it is widespread in certain Nymphalidae subfamilies (Otero, 1990; Mahony, 2006; Lane et al., 2008; King, 2007) (Fig. 1.2). VO appears to be scattered amongst the more derived subfamilies, in particular in the subfamily Satyrinae (Fig. 1.2B; Lane et al., 2008). This suggests that VO is a derived trait, however greater insight into its taxonomic distribution is required to conclude this. Since morphological analysis alone is insufficient to determine whether or not these ears are functional hearing organs, VO must also be described with physiological and behavioural evidence.

Recent experimental evidence supports the hypothesis that the VO functions as a hearing organ. Behavioural evidence has been provided for two satyrine species responding to low frequency sound stimuli. The diurnal butterflies Erebia euryale and Erebia manto (Nymphalidae, Satyrinae, Satyrini) display behavioural responses including wing twitch and escape flight to low frequency, non-specific sound stimuli (Ribaric and Gogala, 1996). The butterflies responded best to a frequency of $1.0 \mathrm{kHz}$ and a sound intensity between 60-70 dB SPL. Importantly, Ribaric and Gogala (1996) found that it was VO that mediated this behavioural response by covering the hearing organ with wax and resin mixture or Vaseline and finding that the behavioural response was terminated. Though the function of hearing remains unknown in this species, they hypothesized that these butterflies may be listening to low-frequency birdcalls. 
Behavioural evidence has also supported a sense of hearing in the crepuscular butterfly species, Manataria maculata, which responds to ultrasonic acoustic stimuli (26 $\mathrm{kHz}$ ) with evasive flight maneuvers. The $26 \mathrm{kHz}$ sound is similar to that of aerialhawking bats (Rydell et al., 2003). Interestingly, this response did not occur when the butterflies were presented the sound stimulus during the day. While the authors observed that M. maculata has potential ears in the form of a $\mathrm{VO}$ at the base of the forewings, they did not test whether it was this organ that was detecting the sound stimuli.

A functional sense of hearing mediated by VO has been demonstrated comprehensively using morphological, neurophysiological, and behavioural evidence in the Blue Cracker Butterfly, Hamadryas feronia (Yack et al., 2000). Male H. feronia produce clicks in interactions with conspecifics and have been shown to respond to these sounds, usually with chasing behaviour. Yack et al. (2000) sought to evaluate all aspects of the acoustic behaviour of these butterflies, and not only analyzed their sound production, but also showed morphologically and physiologically that $H$. feronia has a functional VO that can detect sounds. Physiological recordings showed that the ear has a best frequency of $1.75 \mathrm{kHz}$ at a threshold of $68 \mathrm{~dB}$ SPL, with threshold levels increasing to $90 \mathrm{~dB}$ for frequencies greater than $6 \mathrm{kHz}$. This finding was not expected, as the frequency of the clicks, though broadband, were primarily between $10-15 \mathrm{kHz}$. Behavioural observations however indicate that the butterflies are still able to hear the clicks at natural intensities (Yack et al., 2000). Nevertheless, this study demonstrated experimentally that $H$. feronia does indeed have a functional sense of hearing. Potentially, the H. feronia uses its ear for detecting other acoustic signals, such as to detect predators, which would account for the mismatch in frequencies. 
A third low-frequency ear has been described morphologically and physiologically in the satyrine butterfly Pararge aegeria (Mahony, 2006). This diurnal butterfly, native to northern temperate regions of Europe, has been shown to have a welldeveloped VO as well, that responds to frequencies in the range of approximately 3-18 $\mathrm{kHz}$ (Mahony, 2006). The function of this hearing organ also remains unknown.

Present studies into hearing in the Nymphalidae have focused on the tropical butterfly Morpho peleides (Nymphalidae, Satyrinae, Morphini), more commonly known as the Blue Morpho. This butterfly is indigenous to Central America and can be found from Mexico to Columbia (DeVries, 1987). Morpho peleides is a diurnal butterfly that inhabits second growth forests in the lowlands, premontane, and montane regions where it flies along road cuts, trails, and streams (DeVries, 1987). Studies performed in the Yack lab first observed that $M$. peleides has a pronounced VO at the base of the forewing (Lane et al., 2008). The function of the M. peleides VO is unclear as it is neither preyed upon by bats like $M$. heliconaria, nor does it produce sound like $H$. feronia. To test whether M. peleides does indeed have a functional hearing organ, morphological and physiological studies were performed. The VO was characterized as a tympanal hearing organ located on the ventral aspect of the forewing, and comprises both an inner and outer tympanal membrane (Fig. 1.3A, C) (Lane et al., 2008). It is associated with enlarged tracheal air sacs and sensory organs beneath the membrane, and protected by elongated scales that extend from the posterior cuticle edge. Two branches of the main wing nerve IIN1c, N.II and N.III, innervate the ear. These branches innervate the three chordotonal organs associated with the membrane, where N.II innervates organ COII, and N.III innervates the two organs COIIIa and COIIIb. Physiological studies involving 


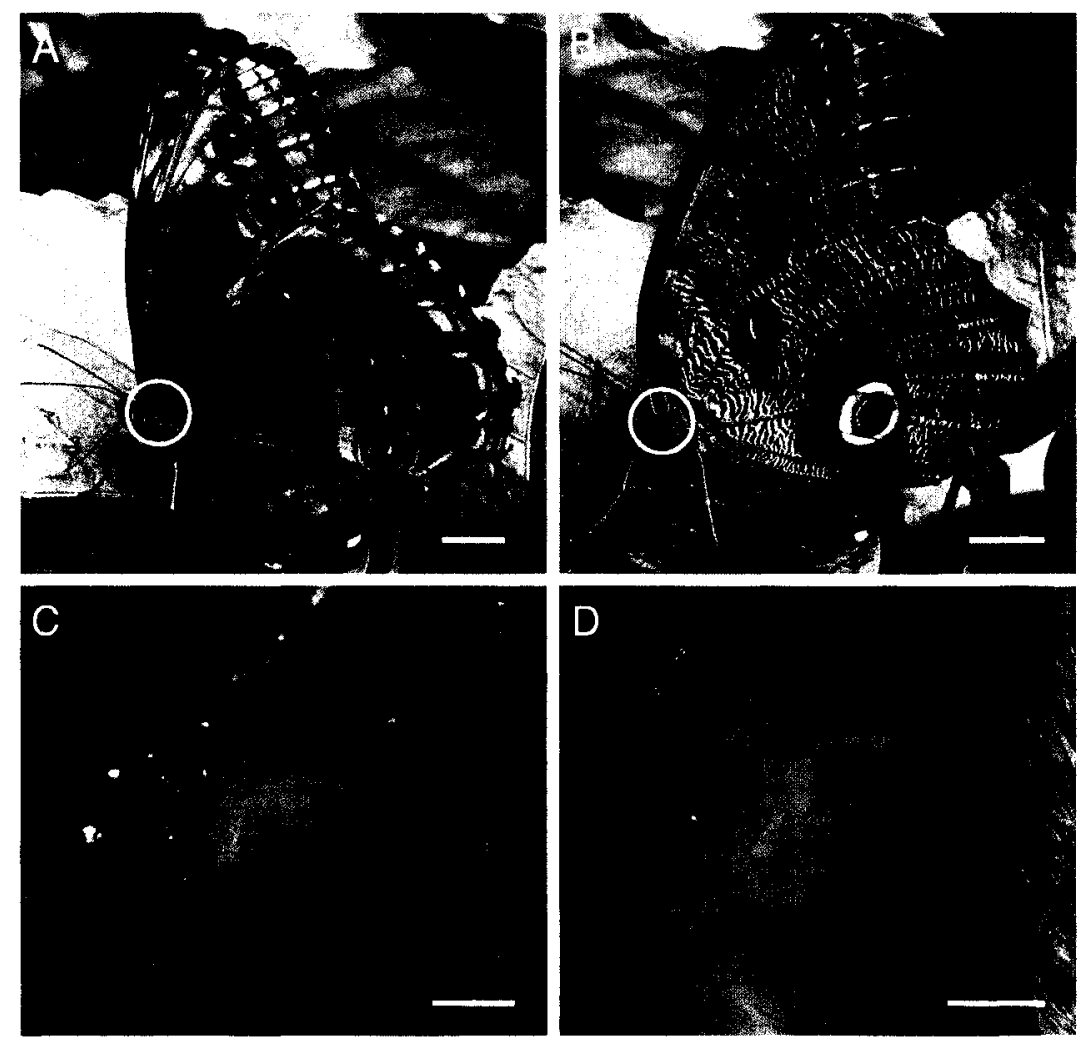

Figure 1.3. Location and external morphology of the Vogel's organ (VO) on the butterfly Morpho peleides. The natural resting position of $M$. peleides, with the VO (circled) exposed on the forewing. (B) Location and external morphology of the VO (circled) on the butterfly Caligo eurilochus. (C) Close-up, M. peleides VO. Scale bar $=300 \mu \mathrm{m}$. (D) Close-up, C. eurilochus VO. Scale bar $=500 \mu \mathrm{m}$. 
extracellular recordings from the nerve branch N.III showed that there was a response to low-frequency sound stimuli between $500 \mathrm{~Hz}$ and $20 \mathrm{KHz}$ (Lane et al., 2008). While studies conclusively showed the $M$. peleides VO was a hearing organ, the significance of its unusual morphology was not explored.

\subsection{Thesis objectives}

Lane et al. (2008) demonstrated that the M. peleides VO has a surprisingly heterogeneous tympanal membrane, consisting of two distinct regions: the bulbous inner membrane and the flat outer membrane (Fig. 1.3C). This structure appears to be unique when compared to other insect ears outside of the butterfly family Nymphalidae. Interestingly, the description of the innervation patterns of this ear suggests that the three chordotonal organs are associated with the inner and outer membrane (Lane et al., 2008). The previous study only tested one of the innervating branches, N.III, therefore only recording the response of two of the three associated chordotonal organs.

The first objective of my thesis will be to assess the functional organization of the M. peleides VO. This will involve (1) describing how the three chordotonal organs are associated with the membrane using histological studies, (2) testing the neurophysiological response of the innervating branch N.II that was not exclusively tested by Lane et al. (2008), and (3) studying the vibrational properties of the tympanal membrane. I will test the hypothesis that $M$. peleides has the capacity for frequency discrimination based on the structural organization of the hearing organ. It is predicted that the inner and outer membrane will have different vibrational properties and will 
therefore transmit different information via the associated chordotonal organs and the two separate innervating branches.

Another question that remains unanswered regarding the $M$. peleides hearing organ is its ultimate function. Lane et al. (2008) hypothesized that the low-frequency ear in $M$. peleides and other diurnal, mute butterflies is equipped to detect the flight sounds of avian predators. Birds are a major predator and strong selective pressure against butterflies, and are considered one of the primary reasons why selection has resulted in the high variability in the morphology, physiology, and behaviour of butterflies (Chai, 1996). Selection for defensive traits has led to the variety of colouration found in butterflies, whose functions include aposematism, startle, and mimicry (Bowers et al., 1985; Marden and Chai, 1991; Chai and Srygley, 1990). Butterflies are susceptible to predation in flight, especially by birds that detect prey visually, who have been observed to successfully attack and capture butterflies in flight as well as at rest (Chai and Srygley, 1990). The low frequency, broadband pattern of hearing that some butterflies possess ( $M$. peleides, $P$. aegeria, Erebia spp.) would be well tuned for listening to approaching avian predators. In particular, they may be listening to the sounds of the approaching bird flight, which are broadband, low-frequency sounds (Mahony, 2006; Lane et al., 2008). It is therefore a likely explanation as to why such a wide diversity of butterflies possesses VO.

The second objective of my thesis is to test the avian hypothesis by comparing the M. peleides ear with that of a closely related species, Caligo eurilochus. These two species are members of sister taxa (Morphini and Brassolini respectively), and until recently were part of the same subfamily 'Morphinae' (Pena et al., 2006). They have 
consistently been shown to be closely related in butterfly phylogenies (Brower, 2000; Freitas and Brown, 2004; Wahlberg et al., 2003). These neotropical butterflies provide an excellent study model for testing the avian hypothesis: the Morphini are primarily diurnal and preyed upon by birds (DeVries, 1987; Penz and DeVries, 2002), whereas the Brassolini are crepuscular, and therefore most likely relieved from avian predation (DeVries, 1987; Srygley, 1994). For the most part, the Brassolini butterflies remain lethargic during the daylight hours (Srygley, 1994). Since they are palatable (Marden and Chai, 1991), it has been suggested that their crepuscular behaviour is a defense (DeVries, 1987). They are also cautious in their activity during the dawn and dusk, and some species have been observed to occupy their territories for only 15 minutes (Caligo idomenaeus, Freitas et al., 1997). Their geographical range overlaps with that of the Morphini, from Mexico down through Central and South America (DeVries, 1987). Preliminary morphological analysis of VO in C. eurilochus indicates that while the hearing organ is present in this species, its structure appears less complex than that of $M$. peleides (Fig. 1.3B, D). The first goal of this section will be to test whether C. eurilochus has a functioning VO using neurophysiology and laser vibrometry. Next, the functionality of VO in C. eurilochus will be compared to M. peleides to determine whether differences in their life histories may have played a role in different sensory adaptations. Ultimately, this will provide evidence that associates differences in VO structure and function with differences in predation, providing a future platform with which to test the avian hypothesis. 


\title{
Chapter 2.
}

\section{The functional significance of the tympanal membrane and associated chordotonal organs in the novel hearing organ of the tropical butterfly, Morpho peleides (Papilionoidea, Nymphalidae)}

\author{
Manuscript in preparation for the Journal of Experimental Biology
}

\subsection{Introduction}

Insects display an impressive diversity of acoustic sensory organs that play key roles in detecting predators and prey, social communication, and navigation. Acoustic sensory organs can be broadly categorized as either vibration, near-field or far-field receptors (Yager, 1999; Yack, 2004). Vibration receptors detect substrate-borne vibrations, while near-field sensory organs detect the close-range particle component of sound that generally encompasses frequencies below $1 \mathrm{kHz}$ (Yack, 2004). Far-field sensory organs such as tympanal ears detect the air-borne pressure component of sounds and can detect frequencies ranging from a few kilohertz to over $100 \mathrm{kHz}$ (Yack, 2004). Insect tympanal hearing organs share three common structural elements, comprising a thinned region of cuticle acting as a tympanal membrane, innervating chordotonal organs, and associated tracheal air sacs (reviewed in Yager, 1999; Yack, 2004). Despite this common bauplan, insect ears have been found to occur on any part of the body, and to vary with respect to both the number and location of sensory receptors, as well as the thickness and topography of the membrane. Presumably, this remarkable variation in structure is associated with function to provide a selective advantage. 
The wide diversity in insect tympanal hearing organs can also be observed in the heterogeneous topographies of their tympanal membranes. As the first unit of the hearing organ to respond to a sound stimulus, the membrane is crucial in the transduction of a physical sound to a neural signal. Variation in the membrane can therefore affect what the ear detects. For example, the structure of the tympanal membrane with relation to the attachment points of sensory cells has been found to be a key factor in frequency discrimination in locusts and cicadas (Michelsen, 1971a; Windmill et al., 2005; Sueur et al., 2006). In locusts, mechanical energy is channeled to the specific locations on the membrane where distinct groups of sensory neurons attach through the propagation of travelling waves (Windmill et al., 2005). The tympanal membrane of the cicada undergoes similar mechanical vibrations, which results in the decomposition of an incoming conspecific sound stimulus into its high and low frequency components along a portion of the membrane (Sueur et al., 2006). The mechanical characteristics of the tympanal membrane in moths have also been implicated in a non-linear mechanical response to ultrasound stimuli (Windmill et al., 2006; 2007). As the intensity of an incoming sound stimulus increases, so too does the resonant frequency of the moth tympanal membrane, which corresponds to the natural increase in frequency in attacking bat echolocation calls (Windmill et al., 2006). The role of membrane mechanics can therefore provide important insight into the significance of the impressive morphological diversity of insect ears.

One insect group receiving new attention with respect to tympanal hearing organs is the butterflies. Vogel's organ (VO) was first described in a satyrine butterfly, and is characterized by a membranous structure located at the base of the cubital vein of the 
forewing associated with tracheal air sacs and chordotonal organs (Vogel, 1912). Recent studies have shown that a wide variation exists in both the structure and function of these ears. These include the high-frequency bat detectors in the hedylid butterfly Macrosoma heliconaria (Yack and Fullard, 2000; Yack et al., 2007) and the nymphalid Manataria maculata (Rydell et al., 2003), and low frequency ears detecting conspecific clicks in Hamadryas feronia (Yack et al., 2000). Other low frequency ears have been described in diurnal, non-sound producing butterflies in such species as Erebia manto and Erebia euryale (Ribaric and Gogala, 1996), Pararge aegeria (Mahony, 2006), and Morpho peleides (Lane et al., 2008). The function of these low-frequency ears is hypothesized to be for detecting the sounds of approaching avian predators (Lane et al., 2008; Mahony, 2006).

The tropical Blue Morpho butterfly, Morpho peleides, is of particular interest due to its unusual tympanal morphology (Lane et al., 2008). The M. peleides VO has an oval-shaped membrane with a discrete convex component in the middle of the structure, dubbed the 'inner' membrane versus the surrounding flat 'outer' membrane (Lane et al., 2008) (Fig. 2.1). Furthermore, there is preliminary evidence that individual sensory organs are associated with each of these. We hypothesize that these membranes vibrate differently, imparting different frequency sensitivities to the corresponding chordotonal organs. We are testing the hypothesis that the $M$. peleides membrane acts to respond preferentially to different frequency ranges based on the different vibrational properties of the two membrane components. With improved techniques, tympanal membranes can now be studied using nanoscale technology to discern subtle vibrational characteristics and relate these to physiological properties of the ear. The goals of this chapter are to (1) 

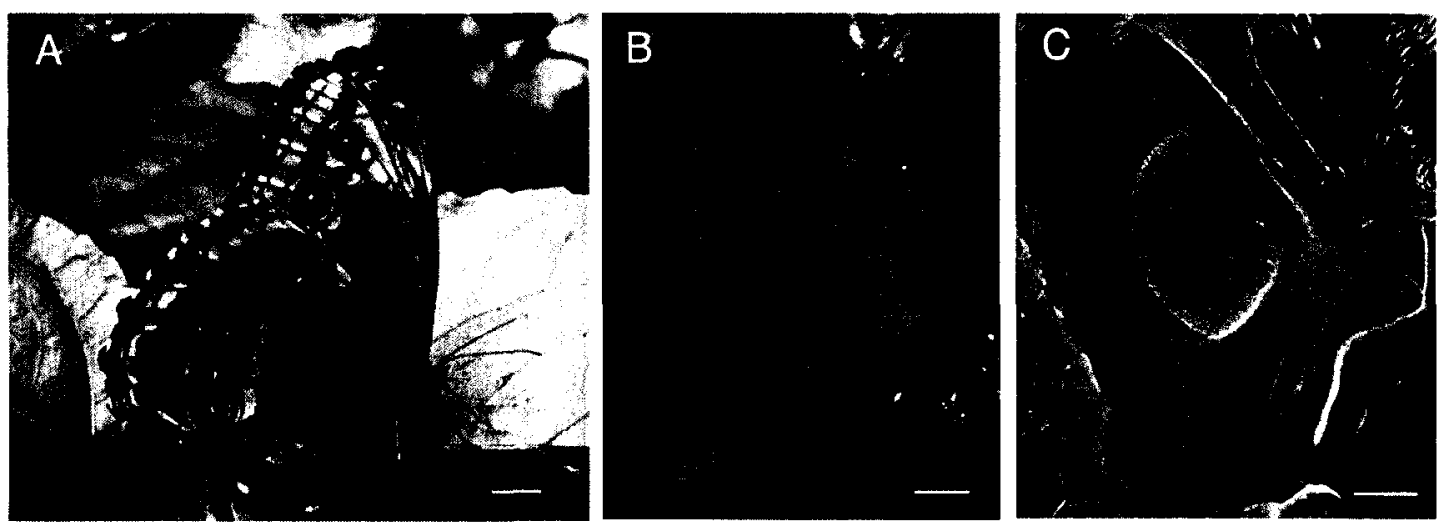

Figure 2.1. Location and external morphology of the Vogel's organ (VO) on the butterfly Morpho peleides.

(A) The natural resting position of $M$. peleides, with the VO exposed on the forewing. Scale bar $=1 \mathrm{~cm}$.

(B) Close-up of VO, scale bar $=200 \mu \mathrm{m}$. (C) Close-up of VO, scale bar $=200 \mu \mathrm{m}$. 
describe the relationship between the membrane and its innervating chordotonal organs, (2) describe the vibrational properties of the non-uniform tympanal membrane, and (3) test the activity of separate nerve branches that innervate the ear to determine whether they respond independently to different frequencies.

\subsection{Materials and Methods}

\subsubsection{Animals}

Morpho peleides Kollar were obtained as pupae from London Pupae Sales (Oxfordshire, UK: Permit number P-2007-01460). At Carleton University, the pupae were kept in a wire mesh enclosure inside a greenhouse, where the cage was exposed to normal light levels, high humidity, and daily temperature fluctuations between $24-35^{\circ} \mathrm{C}$. At the University of Bristol, pupae were kept in mesh cages inside an incubator set at 28 ${ }^{\circ} \mathrm{C}$ and $80 \%$ humidity. Upon eclosion, animals were transferred to a large (approx. $50 \mathrm{x}$ $50 \times 100 \mathrm{~cm})$ cage at room temperature $\left(24-25^{\circ} \mathrm{C}\right)$. Adult butterflies were provided with fermented fruit until they were used for experiments typically 1-5 days following emergence.

\subsubsection{Histology}

Animals were injected with 3\% gluteraldehyde in Sorensen's buffer (Glauert, 1975) into the mesothorax where the fixative could infiltrate up into the forewing, through the ear and into adjoining wing veins. The wing base, including the VO, was removed and submerged in fixative, and was then placed under vacuum for 30 minutes to 
remove air bubbles. The specimens were dehydrated in ethanol, then embedded in Spurr's epoxy (Canemco, Lakefield, QC, Canada). Embedded VOs were sectioned at 1-2 $\mu \mathrm{m}$ using a Reichart-Jung Ultracut $\mathrm{E}$ microtome using glass knives produced from an LKB 7800 B Knife-Maker (LKB Instruments, Mt Waverley, Australia). The sections were stained with $0.1 \%$ Toluidine blue in $1 \% \mathrm{M}$ borax solution (Pillsbury, 1980), and were then observed using a Zeiss (Oberkochen, Germany) Axio Imager.M1 compound microscope equipped with a Zeiss AxioCam MRm camera (1.4 mega pixels, $1388 \times$ 1040) and AxioVision AC (Release 4.6) software. Photographs were assembled and adjusted to optimize brightness and contrast using Adobe Photoshop 7.0 (San Jose, CA, USA).

\subsubsection{Laser vibrometry}

Tympanal vibrations of the VO were examined in response to wideband (chirp) signals between $0.1-30 \mathrm{kHz}$. This frequency range was chosen to encompass the hearing range of $M$. peleides that had been determined in preliminary neurophysiological recordings.

Equipment set-up: Sound signals were generated using a PCI data acquisition board (PCI-4451; National Instruments, Austin, TX, USA), amplified (Amplifier Model TAFE570; Sony, Tokyo, Japan), and projected from one of two loudspeakers ((1) 130kHz, ESS AMT-1; ESS Laboratory inc., Sacramento, CA, USA; (2) 100-1000 Hz, AP100MO, diameter: $117 \mathrm{~mm}$; AUDAX, Chateau du Loir, France). Vibration velocities were measured using a microscanning laser Doppler vibrometer (PSV-300-F; Polytec, Waldbronn, Germany) with an OFV-056 scanning head fitted with a close-up video 
attachment, allowing for the laser spot $(\sim 1 \mu \mathrm{m}$ diameter $)$ to be positioned with an accuracy of $\sim 5 \mu \mathrm{m}$. All experiments were carried out on a vibration isolation table (TMC 784-443-12R; Technical Manufacturing Corp., Peabody, MA, USA) at room temperature $\left(24-26^{\circ} \mathrm{C}\right)$ with a relative humidity of $40-62 \%$, in an acoustic isolation booth (IAC series 1204A; Industrial Acoustics, Bronx, NY, USA).

Recording from M. peleides: The butterflies were positioned upright, attached ventral side down to a brass bar $(6 \times 1 \times 16 \mathrm{~mm})$ using BLU-TACK (Bostik-Findley, Stafford, UK), with wings clasped above using a paper clip to expose the VO. The brass bar was connected to a metal rod, which provided control in correctly positioning the animal for scanning. The legs of the butterflies were cut back before attachment. Scan arrays were set to encompass the entire tympanal membrane of the VO, which was set perpendicular to the direction of the loudspeaker. When possible, both the left and right VOs were scanned for an individual butterfly. A single scan consisted of $>200$ measurement points, and each point was sampled 16 times throughout the scan, resulting in scan durations of approximately 7-10 minutes. The sound pressure level of the acoustic stimulus, projected from a loudspeaker positioned approximately $20 \mathrm{~cm}$ from the specimen, was recorded next to the VO of the specimen using a B\&K Type 4138 pressure-field microphone and a B\&K 2633 preamplifier (Brüel \& Kjær, Nærum, Denmark). The microphone was calibrated at $1 \mathrm{kHz}, 94 \mathrm{~dB}$ SPL using a Brüel \& Kjær 4231 sound level calibrator. Recordings were made when the sound stimulus was at approximately $18-20 \mathrm{mPa}$ (where $20 \mathrm{mPa}$ corresponds to $60 \mathrm{~dB} \mathrm{SPL}$ ) with constant amplitude across the range of frequencies (computer corrected, as described in Windmill et al. 2007). The signals were sampled at $102.4 \mathrm{kHz}$, and a frequency spectrum was produced for each signal with a 
resolution of $12.5 \mathrm{kHz}$ using an FFT (Fast Fourier Transform) with a rectangular window. The amount of unrelated noise was estimated by calculating the magnitudesquared coherence (see Windmill et al. 2007), where a value was assigned between 0 and 1 (a value of 1 indicates the absence of external, unrelated noise). Data were only used when coherence exceeded 0.85 .

\subsubsection{Neurophysiology}

Animals were tethered dorsal side up on a piece of modelling clay. In order to ensure the VO was unobstructed, the forewing was placed on top of the hind wing, the wings were trimmed to $\sim 2 \mathrm{~cm}$ in length, and a groove was made in the modelling clay to allow acoustic stimuli to reach the hearing organ from speakers aligned at the same height as the specimen. The main wing nerve IIN1c, which branches into three branches (Fig. 2.2, Lane et al., 2008), were accessed by removing the tegula and associated membrane. The activity of the two branches that innervate the VO, N.II and N.III, were tested using a stainless steel hook electrode referenced to a second stainless steel electrode placed in the thorax. When a single branch was successfully hooked (N.II or N.III), all other branches of IIN1c were severed to ensure recorded signals were only from the focus branch. To prevent desiccation, the preparation was covered in petroleum jelly when successful recordings were achieved. Neural signals were amplified with a Grass P15 AC preamplifier (West Warwick, RI, USA) and displayed on a Tectronix (Beaverton, ON, Canada) THS720A digital oscilloscope. Neural activity and the associated sound stimulus was recorded on a Fostex FR-2 field memory recorder (Gardena, CA, USA) at a sampling rate of $48 \mathrm{kHz}$ and stored as .wav files. All 


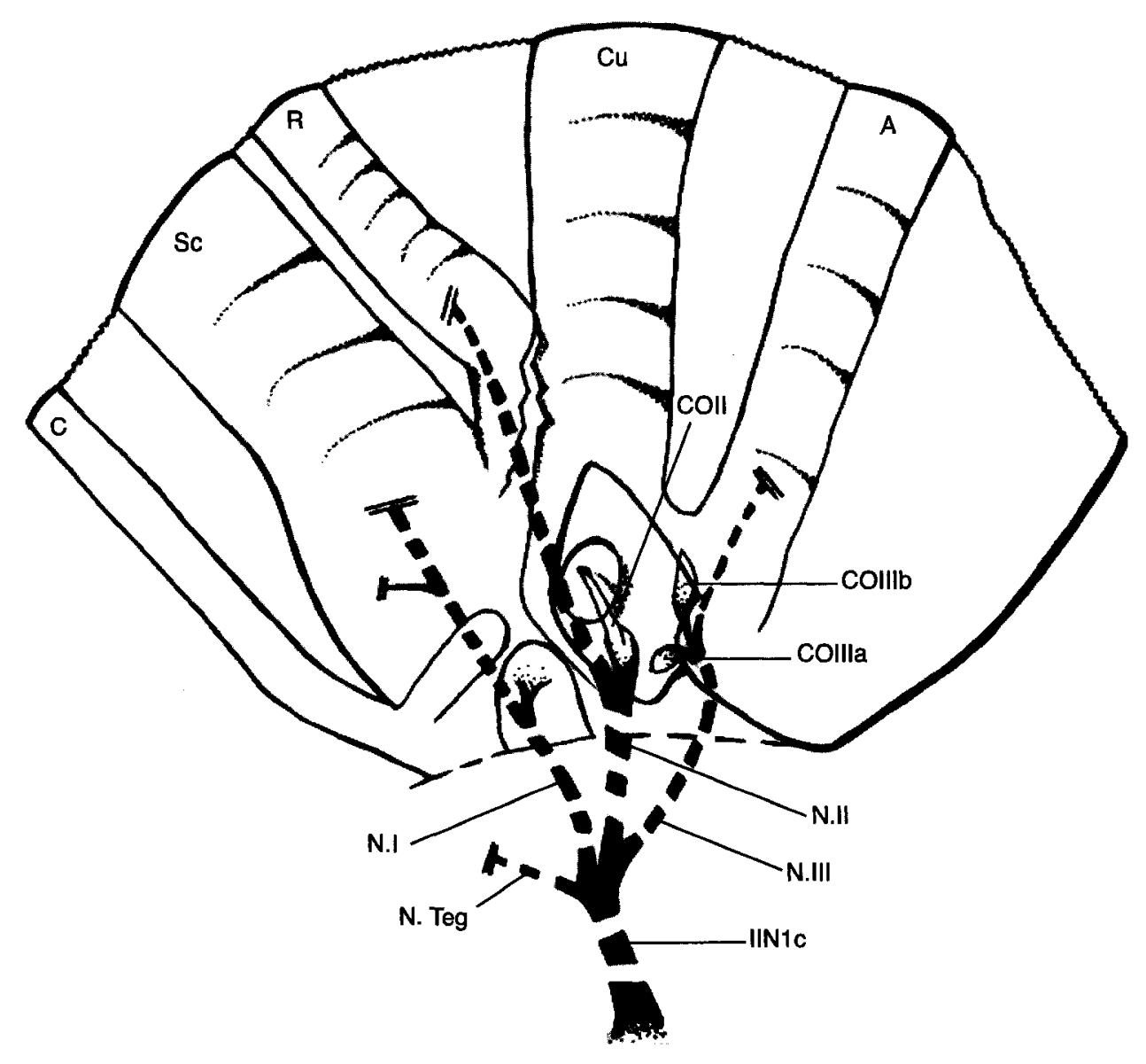

Figure 2.2. Ventral-view schematic illustration of the left mesothoracic wingbase and Vogel's organ in Morpho peleides (anterior is to the left). The main wing nerve IINlc divides into the four branches N.Teg, N.I, N.II, and N.III. The three primary wing nerve branches are represented by dotted lines indicating they lie under membraneous cuticle. N.I travels up the subcostal (Sc) vein and does not enter the Vogel's organ. N.II innervates COII, which attaches to the middle of the inner membrane, then continues up the radial (R) vein. N.III innervates $\mathrm{COIIIa}$ and $\mathrm{COIIIb}$, which are associated with the base of the outer membrane, then continues up the anal (A) vein. Adapted from Lane et al. (2008). 
preparation and recordings were performed within a Faraday cage lined with acoustic foam $(1.22 \times 0.89 \times 0.84 \mathrm{~m})$.

Acoustic stimuli between $0.5-36 \mathrm{kHz}$ were presented as trapezoidal sound pulses (30 ms duration, 5ms rise/fall, linear ramp) shaped using PC Tucker Davis software (RpvdsEx, v. 5.4; Alachua, FL, USA) and synthesized by a Tucker Davis Technologies (TDT) digital signal processor (RX6 multifunction processor). Sound pulses between 500 and $3000 \mathrm{~Hz}$ were attenuated by a TDT SAl stereo power amp and broadcast from a generic six-inch woofer at $80 \mathrm{~cm}$ from the specimen. The sound intensity of these stimuli were calibrated to $\mathrm{dB}$ SPL (reference pressure $20 \mu \mathrm{Pa}$ ) by casting a 1 -second sine wave, generated with the TDT digital signal processor, to a Brüel \& Kjær Type 2239 sound level meter (Nærum, Denmark). Stimuli between 3 and $36 \mathrm{kHz}$ were attenuated using a TDT PA5 programmable attenuator and broadcast from a two-inch cone tweeter (GT1016, Q-components, Waterloo, ON) and calibrated using a Brüel \& Kjær Type 4135 $6.35 \mathrm{~mm}$ microphone and type 2610 Brüel \& Kjær measuring amplifier.

Audiograms were constructed to characterize and compare the auditory range of the individual innervating branches of the M. peleides VO. Frequencies between 0.5 and $36 \mathrm{kHz}$ were tested in random order at approximately $1 \mathrm{kHz}$ intervals. Threshold was calculated by gradually decreasing the sound intensity of the stimulus, and was determined to be the lowest intensity at which neural spikes could consistently be heard in synchrony with the sound stimulus by two independent observers. To determine if the neural responses recorded were sensory, we measured the latency of the neural response to the sound stimulus from .wav files recorded on a Fostex FR-2 field memory recorded for later analysis using Audacity 1.2.5 software (Free Software Foundation, Boston, MA). 
An average latency from four neural responses was calculated per specimen. This was performed at the same sound intensity for each individual.

\subsection{Results}

\subsubsection{Morphology}

The M. peleides VO is located on the ventral side of the forewing at the base of the cubital, subcostal, and anal veins (Figs. 2.1, 2.2). In a previous study, Lane et al. (2008) demonstrated that the VO is comprised of the three typical morphological characteristics of an insect ear: a tympanal membrane, enlarged trachea, and chordotonal sensory organs. In this study, we focus specifically on the tympanal membrane and its association with the three chordotonal organs.

The oval-shaped tympanal membrane is made up of two distinct morphological regions. The dome-like inner membrane (IM) rests in the middle of the outer membrane $(\mathrm{OM})$, and is slightly thicker $(4.94 \pm 0.80 \mu \mathrm{m}$ and $3.44 \pm 0.89 \mu \mathrm{m}$ respectively) (Fig. 2.3A). The inner membrane is innervated by the chordotonal organ COII, while the outer membrane is innervated by the two chordotonal organs COIIIa and COIIIb (Figs. 2.2, 2.3). COII, which is supplied by the N.II branch of the main wing nerve IIN1c (Lane et al., 2008), innervates the IM by attaching directly to the middle of the IM via an attachment strand (Figs. 2.3B, 2.4A). The attachment strand extends at an angle towards the proximal region of the tympanal chamber, where the organ attaches at the base (Figs. 2.3D, 2.4B). Scolopale caps can be observed in the base of the organ in a linear array, oriented such that the distal end of the dendrites extend towards the membrane and appear to be at a slight angle, as the organ sits due to the attachment strand. The two other 

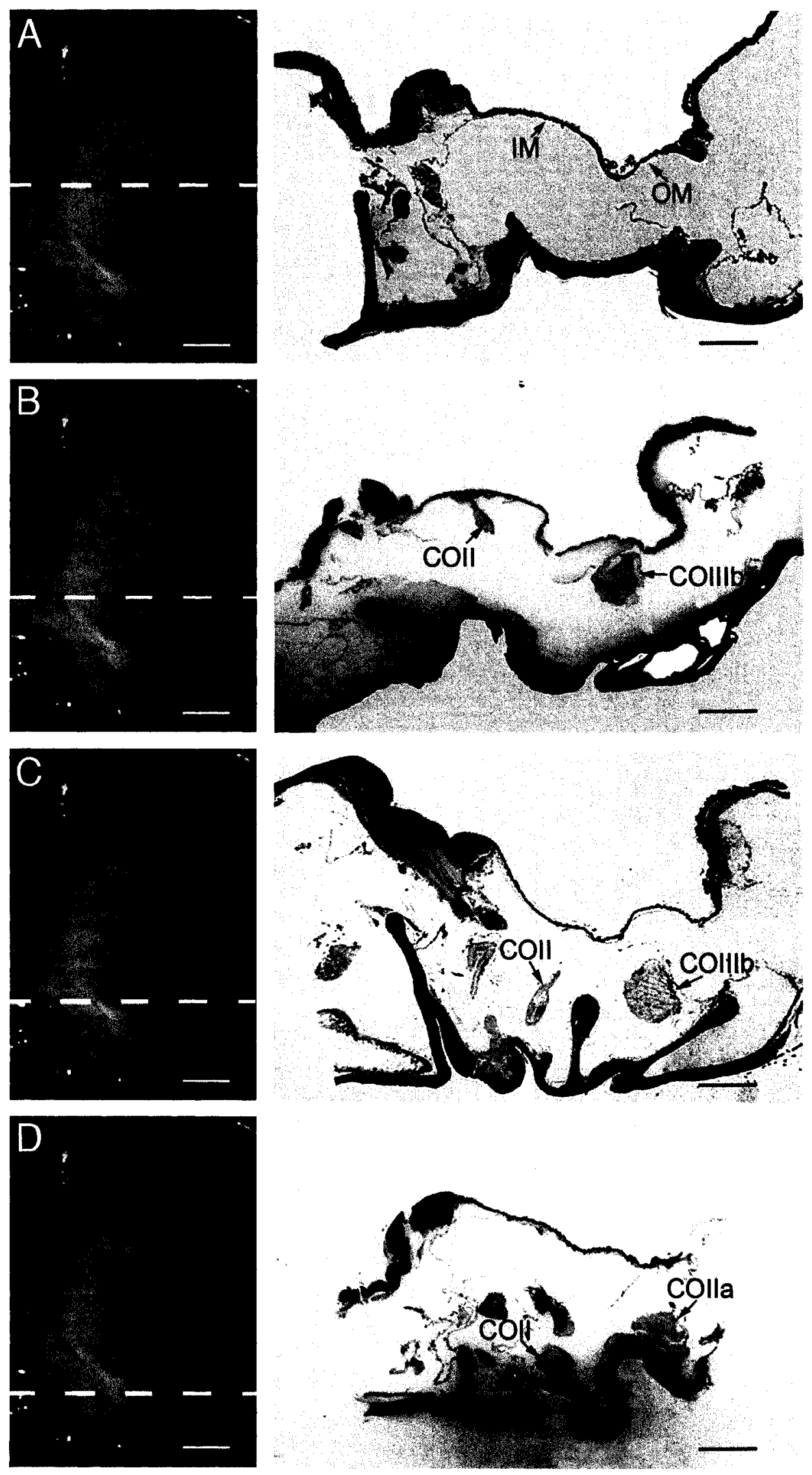
Figure 2.3. Histological sections through the left forewing base of Morpho peleides, oriented such that the anterior edge of the ear is on the left, and the posterior edge is on the right. The approximate locations of the cross-sections are indicated by the dashed line through the light micrograph of Vogel's organ (left), moving from distal to proximal from (A) to (D). (A) Section through the middle of the inner membrane showing both the inner (IM) and outer (OM) membranes. (B) Section through the proximal end of the inner membrane, showing both attachment strand of COII extending from the inner membrane, as well as the beginning of COIIIb resting below the outer membrane, surrounded by associated tracheal tissue. (C) Section through the base of the outer membrane, showing the intermittent structure of COII as it extends towards the base of the tympanal chamber, as well as the end of the COIIIb. (D) Section through the base of the outer membrane, showing COII attached to the base of the tympanal chamber, as well as COIIIa also resting, but not attaching, to the scleretization between the cubital and anal veins at the base of the tympanal chamber. All scale bars $=200 \mu \mathrm{m}$. 


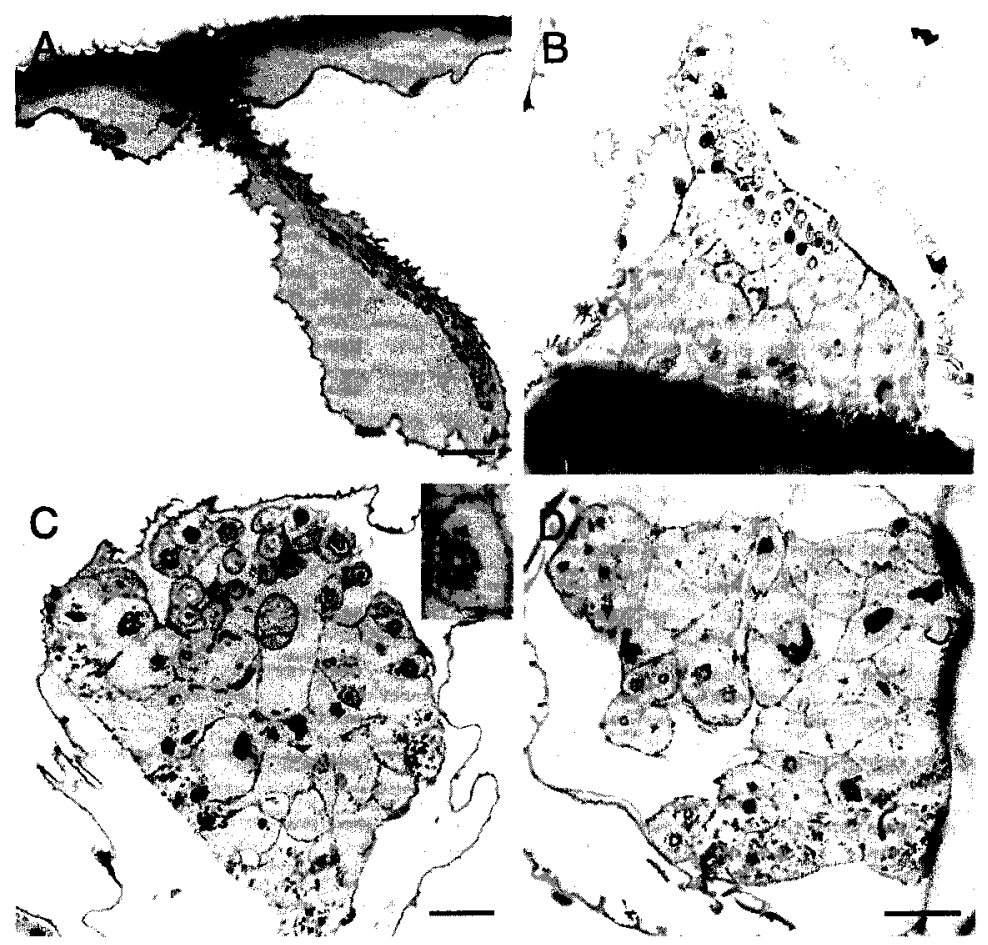

Figure 2.4. Histological sections of the three chordotonal organs in the Morpho peleides Vogel's organ. (A) The attachment strand of COII, attached to the inner membrane via attachment cells. (B) Cross-section of the base of COII, attached to the base of the tympanal chamber. Note the linear arrangement of the scolopale caps at the top of the organ. (C) Cross-section through COIIIb, denoting scolopale caps at the distal end of the section. The inset shows a close-up cross-section of a single scolopidium from COIIIb. (D) Cross-section through COIIIa denoting scolopale caps. Scale bars $=20 \mu \mathrm{m}$. 
chordotonal organs, COIIIa and COIIIb from the nerve branch N.III, innervate the OM at the base of the posterior end. The larger of the two, COIIIb, attaches to the membrane via an attachment strand, and is anchored to the scleretization that divides the cubital and anal veins at the base of the tympanal chamber. The smaller organ, COIIIa, is situated more proximally, and is indirectly associated with the membrane via trachea and its attachment to COIIIb (Fig. 2.4D). The scolopidia in both organs are parallel to the membrane, and oriented such that the scolopale caps extend to the distal end of the VO.

\subsubsection{Vibrational analyses}

The VO of $24 M$. peleides were scanned with a laser Doppler vibrometer to determine the vibrational response of the whole membrane to determine whether the two regions, the inner and outer membranes, have different vibrational properties. A frequency range of $100 \mathrm{~Hz}$ to $30 \mathrm{kHz}$ was tested, which spans the threshold hearing range $(500 \mathrm{~Hz}$ to $19 \mathrm{kHz})$ as determined by Lane et al. (2008). Overall, the membrane was found to vibrate in two modes, depending on the frequency range: at lower frequencies $(0.8$ to $5 \mathrm{kHz})$ the vibration was focused at the base of the posterior end of the outer membrane, while at higher frequencies (greater than $5 \mathrm{kHz}$ ) the entire membrane contributed to the vibration (Fig. 2.5). These two modes correspond to the relative placements of the two sets of chordotonal organs, where the membrane attachment point of COIIIa and b vibrates more at lower frequencies and all three chordotonal organs (including COII) vibrate at higher frequencies.

The displacement gain of the membrane at the two specific attachment sites was analyzed to determine how the chordotonal organs might be stimulated by the membrane 


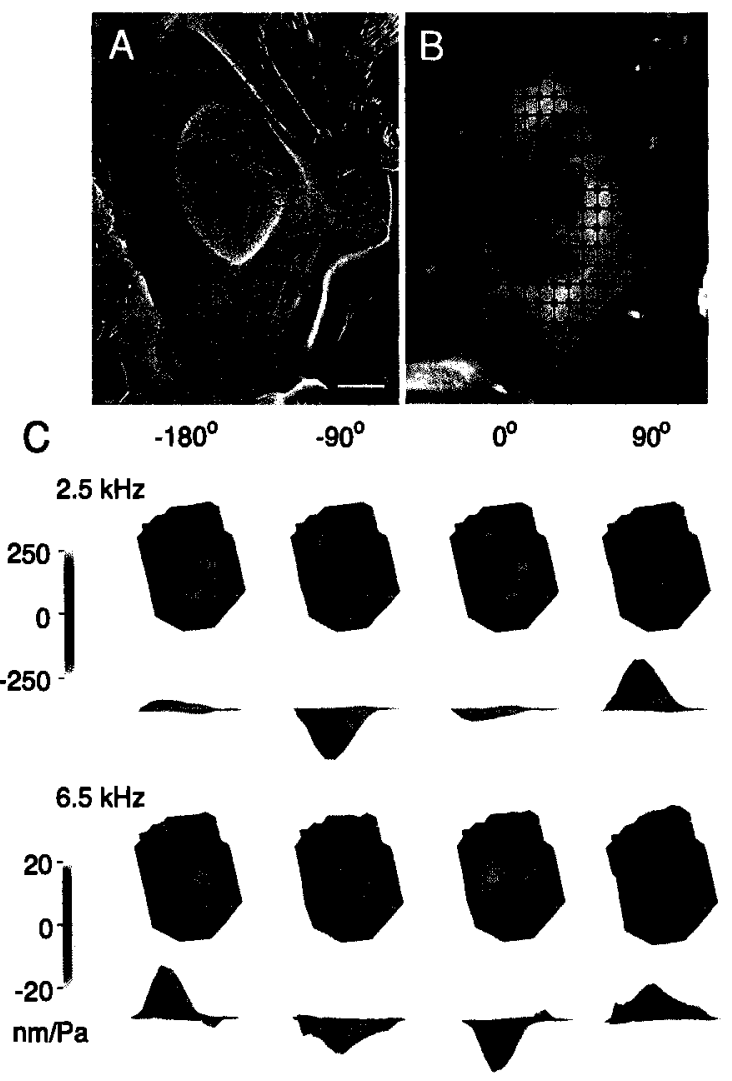

Figure 2.5. (A) Scanning electron micrograph of Morpho peleides' Vogel's organ, whole view of the right tympanal membrane. Scale bar: $100 \mu \mathrm{m}$. (B) Orientation image of the M. peleides tympanal membrane displaying the scan points included in the area scan. (C) Tympanal displacement in response to sound frequencies at $2.4 \mathrm{kHz}$ (above) and $6.5 \mathrm{kHz}$ (below). Each set is shown at four different phases throughout the oscillation cycle. Red indicates positive displacement (or outward tympanal movement) and green indicates negative displacement (or inward tympanal movement). The profile is shown from both a top view and a side view. 
vibration (Fig. 2.6A). This was performed for nine individuals. While both points responded with the greatest amplitude between 1 and $5 \mathrm{kHz}$, the displacement gain at the base of the posterior end of the membrane was approximately two-fold that of the middle of the inner membrane at the lower frequency range $(173.3 \pm 125.5 \mathrm{~nm} / \mathrm{Pa}$ and $82.6 \pm 42.8$ $\mathrm{nm} / \mathrm{Pa}$ at $2.5 \mathrm{kHz}$, respectively). At higher frequencies, the average displacement gain decreased to levels between 10 and $30 \mathrm{~nm} / \mathrm{Pa}$ in both the inner and outer membrane. Therefore, the vibration response of the membrane varies significantly with frequency, with a best frequency of $2-3 \mathrm{kHz}$. The shape of the membrane response across the attachment points, described as the deflection envelope, also varies with the stimulus frequency (Fig. 2.6B). In the lower frequency range, the membrane uniformly vibrates around a single node near the base of the posterior end. At higher frequencies, the membrane appears to vibrate around 2 nodes, one at the very base of the posterior end of the membrane (at its most proximal point), and the next at the inner membrane. Therefore, not only does the membrane displace over a much greater distance at low frequencies, the shape of the whole membrane movement is less complex.

\subsubsection{Neurophysiology}

Two branches, N.II and N.III, innervate the M. peleides VO, from the main wing nerve IIN1c. Previous extracellular nerve recordings focused on the posterior N.III. Our neurophysiological analysis has focused on the middle N.II branch in order to determine whether the separate branches respond differently to the same auditory stimulus. Three recordings were also performed from N.III to ensure our results were consistent with Lane et al. (2008). 

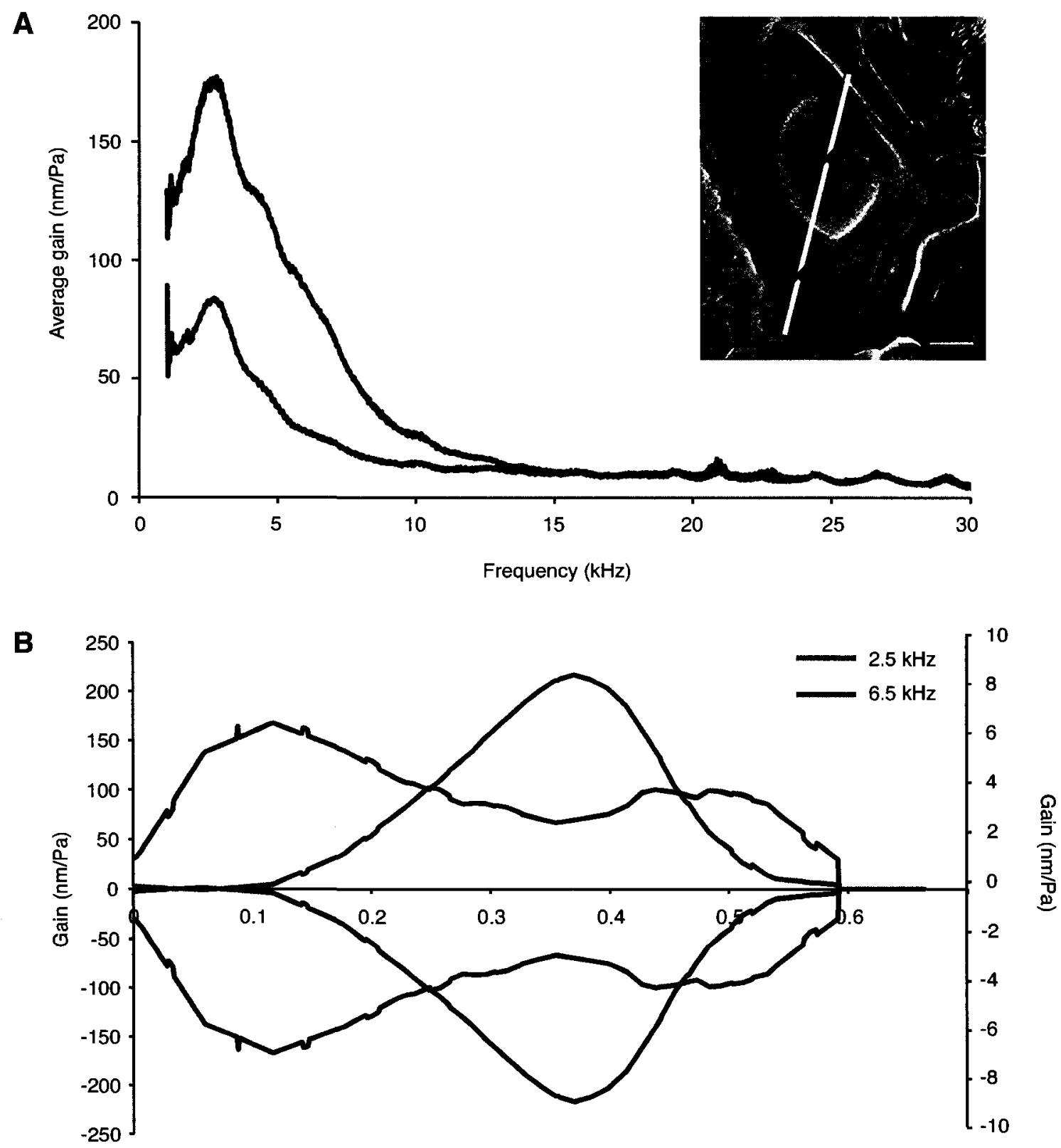

Distance along transect

Figure 2.6. Mechanical response of the Morpho peleides membrane to sound. (A) The average amplitude gain response of two points of the tympanal membrane in response to frequencies between $1-30 \mathrm{kHz}$. The blue line shows the response of the outer membrane, while the red line shows the response of the middle of the inner membrane (specific points tested are denoted on the scanning electron micrograph of Vogel's organ with a blue and red "x", respectively). (B) The deflection envelopes of the amplitude gain response. The left $y$-axis corresponds to the response at $2.5 \mathrm{kHz}$ (blue), while the right y-axis corresponds to the response at $6.5 \mathrm{kHz}$ (red). The transect measured is showed on the scanning electron micrograph of the Vogel's organ with a white line. Scale bar $=200 \mu \mathrm{m}$. 
Six female $M$. peleides were tested using extracellular nerve recordings from N.II. Previous analysis showed there was not a significant sexual dimorphism with respect to the M. peleides VO and its auditory response (Lane et al., 2008). The N.II branch responded consistently to pure tone acoustic stimuli between 0.7 and $20 \mathrm{kHz}$. The response consisted of compound action potentials and was tonic for all stimulus durations tested $(30 \mathrm{~ms}$ to $1 \mathrm{~s})$. The amplitude of the compound action potentials increased with increasing sound intensity, suggesting that more sensory neurons were stimulated at higher sound intensities. At approximately $8 \mathrm{~dB}$ SPL above threshold, latencies ranged between 6 and $9 \mathrm{~ms}$, indicating that the neural response was sensory. Nine audiograms were generated from the six specimens for the N.II branch (Fig. 2.7A). It was found to be most sensitive at frequencies between $1.5-4 \mathrm{kHz}$, with an average threshold of $68 \mathrm{~dB}$ SPL at both 2 and $4 \mathrm{kHz}$. The best threshold for an individual was $52 \mathrm{~dB}$ at $2 \mathrm{kHz}$. There was some response of N.II to frequencies between $21-32 \mathrm{kHz}$ at high sound intensities (generally $>90 \mathrm{~dB}$ SPL), which was a novel finding for M. peleides. When comparing the average threshold response recorded from the N.II branch versus the N.III branch, no significant difference was found with respect to either the sensitivity or the frequency range (Fig. 2.7B).

\subsection{Discussion}

The tympanal membrane, as the first structure to intercept an incoming sound, transmits the mechanical energy of an acoustic stimulus to the sensory organs and essentially determines what sound frequencies and intensities can and will be detected by an insect. The unusual membrane of the $M$. peleides $\mathrm{VO}$ represents a novel tympanal 

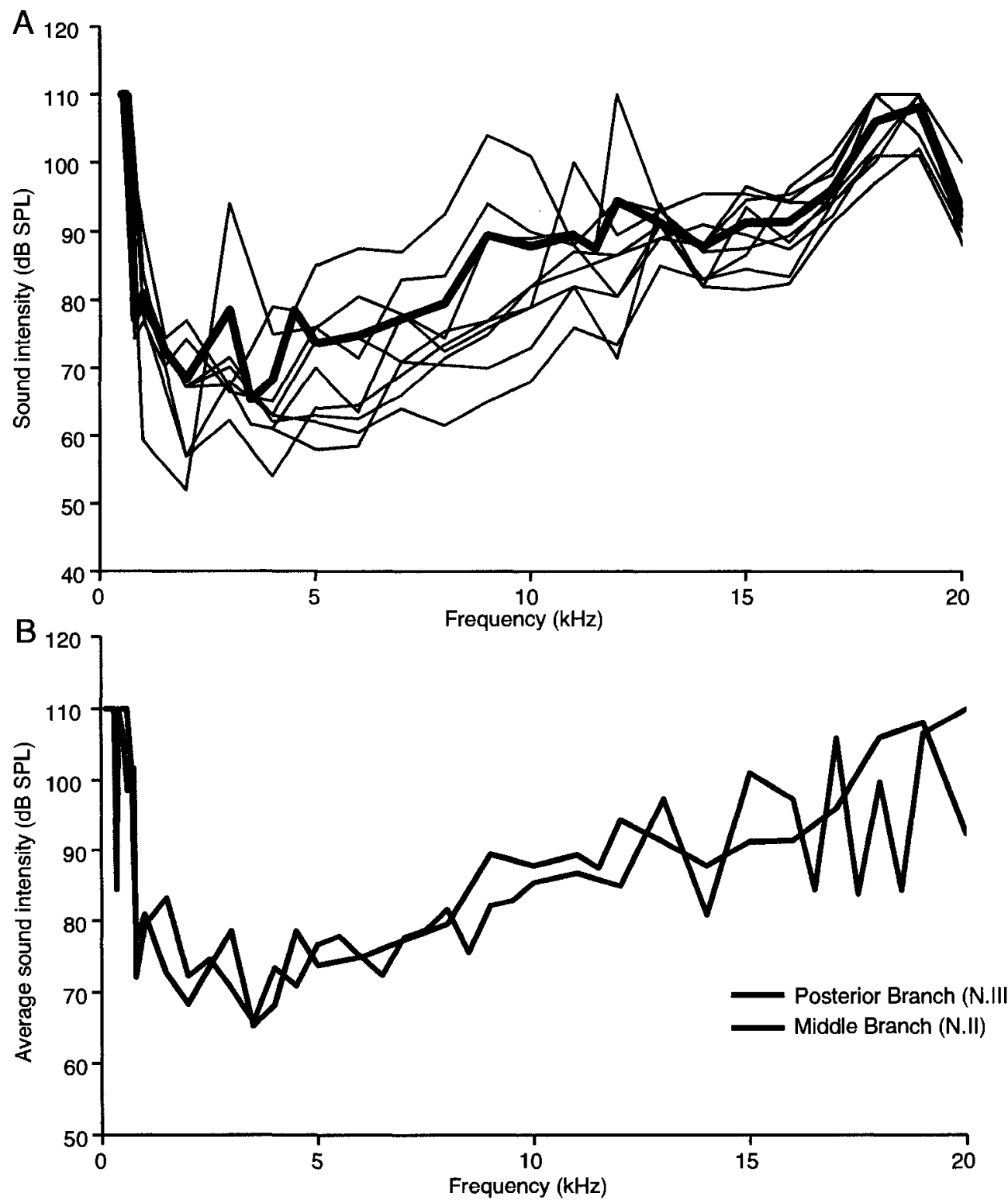

Figure 2.7. Audiograms for Morpho peledies. (A) Response of neural branch N.II, $n=9$. The bold line represents the average threshold response. (B) The average threshold response of the branch N.II (blue) and N.III (red; from Lane et al. 2008). Points at $110 \mathrm{~dB}$ SPL are arbitrary thresholds assigned where no auditory response was detected, and are included in the average value. 
structure in the field of insect bioacoustics. This membrane structure has been described in some other nymphalid butterflies such as Hamadryas feronia (Yack et al., 2000) and Pararge aegeria (Mahony, 2006), however, the M. peleides inner and outer membranes appear to be the most pronounced in our surveys. Given that the chordotonal organs attach to the two different regions of the membrane, we tested to see how the vibration of the membrane corresponds to the morphology of these sensory organs.

Using laser Doppler vibrometry, we found that the tympanal membrane of $M$. peleides vibrates in two frequency-dependent modes. At frequencies below $5 \mathrm{kHz}$, the mechanical response is focused at the proximal region of the posterior end of the outer membrane, while at frequencies above $5 \mathrm{kHz}$, both the inner and outer membranes vibrate in response. This could contribute to gross frequency partitioning by essentially dividing frequencies into two groups, indicating to the animal whether the sound stimulus is at a high or low frequency based on the mechanical tympanal response. The transition between the inner and outer membranes is very abrupt (Figs. 2.1,2.2) and most likely creates the divide between the vibrational modes. Interestingly, the attachment sites of the two sets of chordotonal organs correspond with the focal points of the two vibrational modes. One organ, COII, attaches to the middle of the inner membrane, while the other two organs, COIIIa and COIIIb, are associated indirectly with the base of the posterior end of the outer membrane. This match-up may result in either (1) a broadening of the frequency range detected by the $M$. peleides $\mathrm{VO}$, and/or (2) the ability to detect differences between frequencies. Indeed, frequency discrimination in locusts is achieved by the differential membrane response at different sensory attachment points (Michelsen, 1971a). The sensory organs in the locust Muller's organ are organized into four groups of 
scolopidia that attach to the membrane via attachment strands (Gray, 1960). These four anatomical groups are further categorized into separate functional groups based on their different frequency sensitivities (Michelsen, 1971a; 1971b). Like in M. peleides, the shifting vibrational properties of the locust membrane correspond to the attachment points of the scolopidia, such that different sets of sensory cells are activated in response to the driving frequencies (Windmill et al., 2005). A similar situation is also observed in the cicada, where frequency discrimination is achieved via a travelling wave that is propagated in the heterogeneous membrane in response to sound (Sueur et al., 2006). When the membrane responds to an incoming sound stimulus, the pattern of the vibrations along the tympanal ridge varies with the driving frequency, where the maximal peak of the wave is near the apex of the ridge at higher frequencies and at the base in response to low frequencies (Sueur et al., 2006). Essentially, the tympanal ridge acts as a "frequency analyzer" between $4-10 \mathrm{kHz}$ in males and $6-14 \mathrm{kHz}$ in females by decomposing a sound into its different frequency components (Sueur et al., 2006), which is then conserved into the CNS via finely tuned interneurons (Fonseca et al., 2000). The heterogeneous membrane in $M$. peleides may too transfer different frequency information by activating separate chordotonal organs at either low $(<5 \mathrm{kHz})$ or high $(>5 \mathrm{kHz})$ frequencies. The M. peleides tympanal membrane may yet represent another method to partition, or expand frequency ranges.

Does the complex mechanical behaviour of the $M$. peleides tympanal membrane impart frequency partitioning? The hypothesis was supported by the laser data, but this frequency response must be transmitted to a neural response. To test this, extracellular recordings were performed of the two nerve branches that innervate the two sets of 
chordotonal organs. It would be predicted that the N.III branch, which innervates the two chordotonal organs COIIIa and COIIIb at the base of the outer membrane, would be most sensitive to frequencies between $1-5 \mathrm{kHz}$, corresponding to the first mode of vibration. N.II should respond with the greatest sensitivity to frequencies above $5 \mathrm{kHz}$, corresponding to the second mode of vibration.

In contrast to this prediction, the threshold curves of the two branches did not reveal any significant differences, both with respect to frequency range and threshold. The two branches were most sensitive between $2-4 \mathrm{kHz}$, with best average thresholds between 58 and $62 \mathrm{~dB}$ SPL. There are two possible explanations for this result as far as we can determine. First, that the separate organs have no functional importance with respect to frequency analysis. The frequency partitioning performed by the tympanal membrane is not translated to the nervous system and bears no functional significance. However this seems unlikely in M. peleides, since the pronounced topography of the membrane is more exaggerated than observed in other nymphalid butterfly VOs, such as in $H$. feronia or $P$. aegeria. This suggests the tympanal structure represents a functional adaptation. Nevertheless, this frequency range fractionation does not, at the time, appear to be conserved into the nervous system. A second possibility, which is not mutually exclusive, is that our methods did not extract the differences in frequency response of the separate chordotonal organs. Our extracellular nerve recordings recorded the compound action potentials generated by any responding sensory cells in the chordotonal organs. Any subtle differences in the response of individual sensory cells were not teased out, and intracellular recordings should be performed to address this. Our sample size may also not have been large enough to represent the true average response of the two 
branches, and with more recordings a larger difference in the average response of the two branches would potentially be seen.

Assuming that there is a difference in frequency response, what might be the function in M. peleides? This is not an easy question to answer, as the function of hearing in other widely-studied insects such as the locust still remains unknown. Lane et al. (2008) proposed that $M$. peleides may use its hearing to detect the low-frequency flight sounds of its avian predators, particularly when at rest when its VO is most exposed. When at rest, it exposes the ventral side of its wings which are predominantly brown in colour and are much more inconspicuous than the bright iridescent blue of the wings' dorsal side. It could be important for the butterfly to discriminate whether a bird is attacking, or whether it is simply in the vicinity calling. If it were to respond to all sound stimuli with evasive flight, it would expose its bright colouration and would be at greater risk for predation from surrounding birds. It would therefore be important to be able to distinguish what a bird is doing, and this can be achieved by detecting the difference in frequency range.

We have shown that the vibrational response of the $M$. peleides tympanal membrane has two modes, where the inner and outer membranes show different frequency-dependent patterns of vibration in support of our hypothesis. Our physiology results did not support the hypothesis that the different vibrational responses of the membrane would be translated into the chordotonal organs having different frequency sensitivities. Further research on the hearing of $M$. peleides will focus on expanding the analysis of the neural response of the two branches N.II and N.III. More explicit testing 
of the avian hypothesis using playback and behavioural studies using biologically relevant sound stimuli will also be performed. 


\title{
Chapter 3 .
}

\section{Hearing in the Owl Butterfly Caligo eurilochus (Papilionoidea, Nymphalidae)}

\author{
Manuscript in preparation for the Journal of Comparative Physiology A \\ OR Physiological Entomology
}

\subsection{Introduction}

Research in sound reception in the Lepidoptera has predominantly overlooked an aural sense in butterflies, having instead been focused on hearing in moths. Moths, which make up 43 of the 46 superfamilies of the order Lepidoptera, have been shown to possess tympanal ears that detect high frequency sounds. This has been ascribed to their evolutionary history, where ears have been shown to have evolved independently at least six times to detect the ultrasonic echolocation calls of insectivorous bats (Minet and Surlykke, 2003; Yack, 2004). It is also hypothesized that this predation pressure led to the evolution of the butterflies, which saw a shift from a nocturnal to a diurnal lifestyle (Yack and Fullard, 2000). Assuming the butterfly ancestor had an ear, what would have happened to hearing when the selection pressure was gone?

Recent evidence has shown that while not all butterflies have tympanal ears, many others do. For example, the hedylid butterfly Macrosoma heliconaria has been shown to have a functional hearing organ at the base of the forewing that responds to the ultrasonic calls of insectivorous bats (Yack and Fullard, 2000; Yack et al., 2007). Originally thought to be moths, it is now understood the hedylids are butterflies, and may 
potentially represent the ancestral link between moths and butterflies (Scoble and Aiello, 1990; Yack and Fullard, 2000). Another example of butterfly hearing is in the Blue Cracker butterfly, Hamadryas feronia, which has hearing that functions in conspecific communication, as it is known to elicit clicking sounds during interactions with conspecifics (Yack et al., 2000). Other low frequency ears have been tested in the butterfly species Erebia manto and Erebia euryale (Ribaric and Gogala, 1998), and Pararge aegeria (Mahony, 2006). The function of these low frequency ears, in diurnal species that do not produce sound, remains unknown.

A possible function of the Vogel's organ (VO) in these diurnal, mute butterflies was proposed in Lane et al. (2008) to be for predator detection, namely the flight sounds of approaching avian predators. This study extensively described the hearing capabilities of the tropical butterfly Morpho peleides and found that they listen to low frequency sounds (Lane et al., 2008). Birds are considered one of the primary predators of butterflies and as such are a strong selective pressure against butterflies (Chai and Srygley, 1990; Chai, 1996). Preliminary recordings of bird flight sounds confirmed that the majority of the energy produced from the wings of an approaching predator was below $5 \mathrm{kHz}$ and of sufficient intensity as to be detectable (Mahony, 2006; Lane et al., 2008). The calls of birds are also predominantly low frequency, and it has also been suggested that butterflies could be detecting the calls in order to be aware of the predators around them (Ribaric and Gogala, 1996; Lane et al., 2008; Chapter 2). At present, however, the function of $\mathrm{VO}$ in this and other non-sound producing butterflies remains unknown. 
Another possibility is that there is no significant function of VO in diurnal, mute butterflies, and the organ is vestigial and/or degenerate. Ears have been found to be degenerate in other insect orders when selection for the ear is removed. For example, moths in bat-free habitats either spatially or temporally have been found to have ears that are insensitive to high frequency sounds, as they no longer need to detect the echolocation calls of their main predators (Fullard, 1994; Fullard et al., 1997). This is an interesting factor to consider in the study of butterfly hearing, as morphological surveys suggest that VO exists with varying levels of complexity in many different butterfly species (Otero, 1990; Mahony, 2006; King, 2007). One way to test whether this variation reflects degenerate hearing in the butterflies would be to compare species that do not experience the same selective pressure, in particular that of avian predators. This can be done by comparing M. peleides to the crepuscular butterfly Caligo eurilochus. These two species are members of sister taxa (Morphini and Brassolini respectively), and until recently were part of the same subfamily 'Morphinae' (Pena et al., 2006) (Fig. 3.1). They have consistently been shown to be closely related in butterfly phylogenies (Brower, 2000; Freitas and Brown, 2004; Wahlberg et al., 2003). They also share the same geographical range from Mexico down through Central and South America (DeVries, 1987). While M. peleides is a diurnal butterfly, C. eurilochus is crepuscular and appears to have 'moved into the dark', showing a visual adaptation to the dim light available at dusk and dawn (Fredericksen and Warrant, 2008). For the most part, the Brassolini butterflies remain lethargic during the daylight hours (Srygley, 1994). Since they are palatable (Marden and Chai, 1991; DeVries, 1987), it has been suggested that their crepuscular behaviour is a defense against predators (DeVries, 1987; Srygley, 1994). 


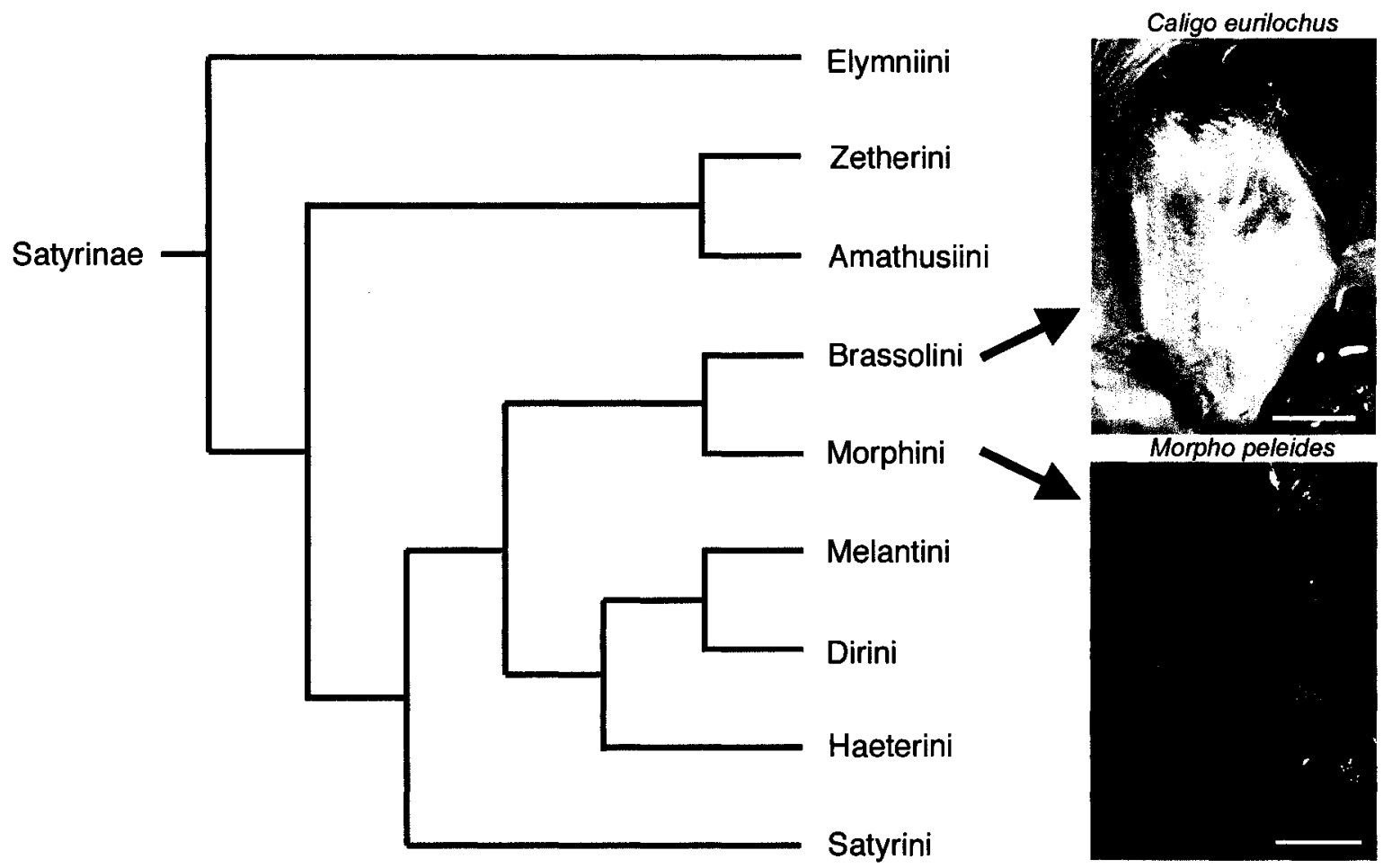

Figure 3.1. Phylogeny of the subfamily Satyrinae (Nymphalidae: Papilionoidea), with representative Vogel's organs from the two tribes Brassolini and Morphini. The Vogel's organ of Caligo eurilochus represent the Brassolini tribes, while Morpho peleides represents the Morphini tribe. Phylogeny adapted from Wahlberg and Brower (2006). Both scale bars $=500 \mu \mathrm{m}$. 
While the M. peleides VO has been described in detail as a functioning, low-frequency ear (Lane et al., 2008; Chapter 2), the C. eurilochus VO has not been studied. Preliminary morphological analysis of $\mathrm{VO}$ in C. eurilochus indicates that while the hearing organ is present in this species, its structure appears more basic than that of M. peleides and potentially represents a degenerate ear (Fig. 3.1).

We will test for the possibility of hearing in C. eurilochus using extracellular nerve recordings and analysis of its tympanal membrane using Doppler laser vibrometry. We predict that the C. eurilochus VO is a potentially degenerate form of the function VO present in its relative M. peleides.

\subsection{Materials and Methods}

Please note the neurophysiology and laser vibrometry methods used for this study are the similar to those stated in Chapter 2.

\subsubsection{Animals}

Caligo eurilochus were obtained as pupae from London Pupae Sales (Oxfordshire, UK: Permit number P-2007-01460). At Carleton University, the pupae were kept in a wire mesh enclosure inside a greenhouse, where the cage was exposed to normal light levels, high humidity, and daily temperature fluctuations between $24-35^{\circ} \mathrm{C}$. At the University of Bristol, pupae were kept in mesh cages inside an incubator set at 28 ${ }^{\circ} \mathrm{C}$ and $80 \%$ humidity. Upon eclosion, animals were transferred to a large (approx. $50 \mathrm{x}$ $50 \times 100 \mathrm{~cm})$ cage at room temperature $\left(24-25^{\circ} \mathrm{C}\right)$. Adult butterflies were provided with 
fermented fruit until they were used for experiments typically 1-5 days following emergence.

\subsubsection{External morphology of $\mathrm{VO}$}

The C. eurilochus VO was described in terms of its general location and qualitative characteristics, and was measured for length, width, and area, with relation to body size. The forewing was removed for each specimen and pinned ventral side up on a Sylgard-lined petri dish (Dow Corning, Midland, MI). VO was photographed and measured using an Olympus SZX12 light microscope (Olympus, Tokyo, Japan) equipped with a Zeiss (Oberkochen Germany) AxioCamMRc5 camera (1.4 megapixels, $1388 \mathrm{x}$ 1040). Measurements of the length, width, and surface area of the membrane were made using AxioVision AC (version 4.6) software. The width of the thorax was also measured as an indicator of body size. For images obtained using scanning electron microscopy, the VO was dissected from live specimens and dried over a minimum of 48 hours, mounted on aluminum stubs, sputter-coated with gold-palladium, and examined with a JEOL (Tokyo, Japan) JSM-6400 scanning electron microscope.

\subsubsection{Neurophysiology}

Animals were tethered dorsal side up on a piece of modelling clay. In order to ensure the VO was unobstructed, the forewing was placed on top of the hind wing, the wings were trimmed to $\sim 2 \mathrm{~cm}$ in length, and a groove was made in the modelling clay to allow acoustic stimuli to reach the hearing organ from speakers aligned at the same 
height as the specimen. The main wing nerve IIN1c, which branches into three branches, were accessed by removing the tegula and associated membrane. The activity of the two branches that innervate the VO, N.II and N.III, were tested using a stainless steel hook electrode referenced to a second stainless steel electrode placed in the thorax. When a single branch was successfully hooked (N.II or N.III), all other branches of IIN1c were severed to ensure recorded signals were only from the focus branch. To prevent desiccation, the preparation was covered in petroleum jelly when successful recordings were achieved. Neural signals were amplified with a Grass P15 AC preamplifier (West Warwick, RI, USA) and displayed on a Tectronix (Beaverton, ON, Canada) THS720A digital oscilloscope. Neural activity and the associated sound stimulus was recorded on a Fostex FR-2 field memory recorder (Gardena, CA, USA) at a sampling rate of $48 \mathrm{kHz}$ and stored as .wav files. All preparation and recordings were performed within a Faraday cage lined with acoustic foam $(1.22 \times 0.89 \times 0.84 \mathrm{~m})$.

Acoustic stimuli between $0.1-31 \mathrm{kHz}$ were presented as trapezoidal sound pulses (30 ms duration, 5ms rise/fall, linear ramp) shaped using PC Tucker Davis software (RpvdsEx, v. 5.4; Alachua, FL, USA) and synthesized by a Tucker Davis Technologies (TDT) digital signal processor (RX6 multifunction processor). Sound pulses between 100 and $3000 \mathrm{~Hz}$ were attenuated by a TDT SAl stereo power amp and broadcast from a CWR 200B50 woofer (Q components, Waterloo, ON) at $80 \mathrm{~cm}$ from the specimen. The sound intensity of these stimuli were calibrated to dB SPL (reference pressure $20 \mu \mathrm{Pa}$ ) by casting a 1-second sine wave, generated with the TDT digital signal processor, to a Brüel \& Kjær Type 2239 sound level meter (Nærum, Denmark). Stimuli between 3 and $31 \mathrm{kHz}$ were attenuated using a TDT PA5 programmable attenuator and broadcast from a two- 
inch cone tweeter (GT-1016, Q components, Waterloo, ON) and calibrated using a Brüel \& Kjær Type $41356.35 \mathrm{~mm}$ microphone and type 2610 Brüel \& Kjær measuring amplifier.

Audiograms were constructed to characterize and compare the auditory range of the individual innervating branches of the C. eurilochus VO. Frequencies between 0.5 and $36 \mathrm{kHz}$ were tested in random order at approximately $1 \mathrm{kHz}$ intervals. Threshold was calculated by gradually decreasing the sound intensity of the stimulus, and was determined to be the lowest intensity at which neural spikes could be consistently heard in synchrony with the sound stimulus by two independent observers. To determine if the neural responses recorded were sensory, we measured the latency of the neural response to the sound stimulus from .wav files recorded on a Fostex FR-2 field memory recorded for later analysis using Audacity 1.2.5 software (Free Software Foundation, Boston, MA). An average latency from five neural responses was calculated per specimen. This was performed at the same sound intensity for each individual.

\subsubsection{Laser vibrometry}

Tympanal vibrations of the VO were examined in response to wideband (chirp) signals between $0.1-30 \mathrm{kHz}$. This frequency range was chosen to encompass the hearing range of C. eurilochus that had been determine in preliminary neurophysiological recordings.

Equipment set-up: Sound signals were generated using a PCI data acquisition board (PCI-4451; National Instruments, Austin, TX, USA), amplified (Amplifier Model 
TAFE570; Sony, Tokyo, Japan), and projected from one of two loudspeakers ((1) 130kHz, ESS AMT-1; ESS Laboratory inc., Sacramento, CA, USA; (2) 100-1000 Hz, AP100MO, diameter: $117 \mathrm{~mm}$; AUDAX, Chateau du Loir, France). Vibration velocities were measured using a microscanning laser Doppler vibrometer (PSV-300-F; Polytec, Waldbronn, Germany) with an OFV-056 scanning head fitted with a close-up video attachment, allowing for the laser spot $(\sim 1 \mu \mathrm{m}$ diameter $)$ to be positioned with an accuracy of $\sim 5 \mu \mathrm{m}$. All experiments were carried out on a vibration isolation table (TMC 784-443-12R; Technical Manufacturing Corp., Peabody, MA, USA) at room temperature $\left(24-26^{\circ} \mathrm{C}\right.$ ) with a relative humidity of $40-62 \%$, in an acoustic isolation booth (IAC series 1204A; Industrial Acoustics, Bronx, NY, USA).

Recording from C. eurilochus: The butterflies were positioned upright, attached ventral side down to a brass bar $(5 \times 1 \times 60 \mathrm{~mm})$ using BLU-TACK (Bostik-Findley, Stafford, UK), with wings clasped above using a paper clip to expose the VO. The brass bar was connected to a metal rod, which provided control in correctly positioning the animal for scanning. The legs of the butterflies were cut back before attachment. Scan arrays were set to encompass the entire tympanal membrane of the VO, which was set perpendicular to the loudspeaker. When possible, both the left and right VOs were scanned for an individual butterfly. A single scan consisted of $>200$ measurement points, and each point was sampled 16 times throughout the scan, resulting in scan durations of approximately 7-10 minutes. The sound pressure level of the acoustic stimulus, projected from a loudspeaker positioned approximately $20 \mathrm{~cm}$ from the specimen, was recorded next to the VO of the specimen using a B\&K Type 4138 pressure-field microphone and a B\&K 2633 preamplifier (Brüel \& Kjær, Nærum, Denmark). The microphone was calibrated at 1 
kHz, 94 dB SPL using a Brüel \& Kjær 4231 sound level calibrator. Recordings were made when the sound stimulus was at approximately $18-20 \mathrm{mPa}$ (where $20 \mathrm{mPa}$ corresponds to $60 \mathrm{~dB}$ SPL) with constant amplitude across the range of frequencies (computer corrected, as described in Windmill et al. 2007). The signals were sampled at $102.4 \mathrm{kHz}$, and a frequency spectrum was produced for each signal with a resolution of $12.5 \mathrm{kHz}$ using an FFT (Fast Fourier Transform) with a rectangular window. The amount of unrelated noise was estimated by calculating the magnitude-squared coherence (see Windmill et al., 2007), where a value was assigned between 0 and 1 (a value of 1 indicates the absence of external, unrelated noise). Data were only used when coherence exceeded $85 \%$.

\subsection{Results}

\subsubsection{Morphology}

The C. eurilochus VO is located at the base of the forewing on the ventral side at the base of the cubital vein (Fig. 3.2). The organ is comprised of a thin membrane anchored by surrounding cuticle most pronounced on the anterior side of the organ. The membrane is almost completely flat, with a few wrinkles that suggest it is not pulled completely taut. The membrane is oval in shape, with an average length of $1915.18 \pm 377.74$, width of $1074.76 \pm 87.56$, with an average area of $1.66 \pm 0.33 \mathrm{~mm}^{2}$. It is predominantly translucent white with a slight darker tan spot in the middle of the anterior side of the membrane. The membrane is covered in non-socketed microtrichia (Fig. 3.3) 

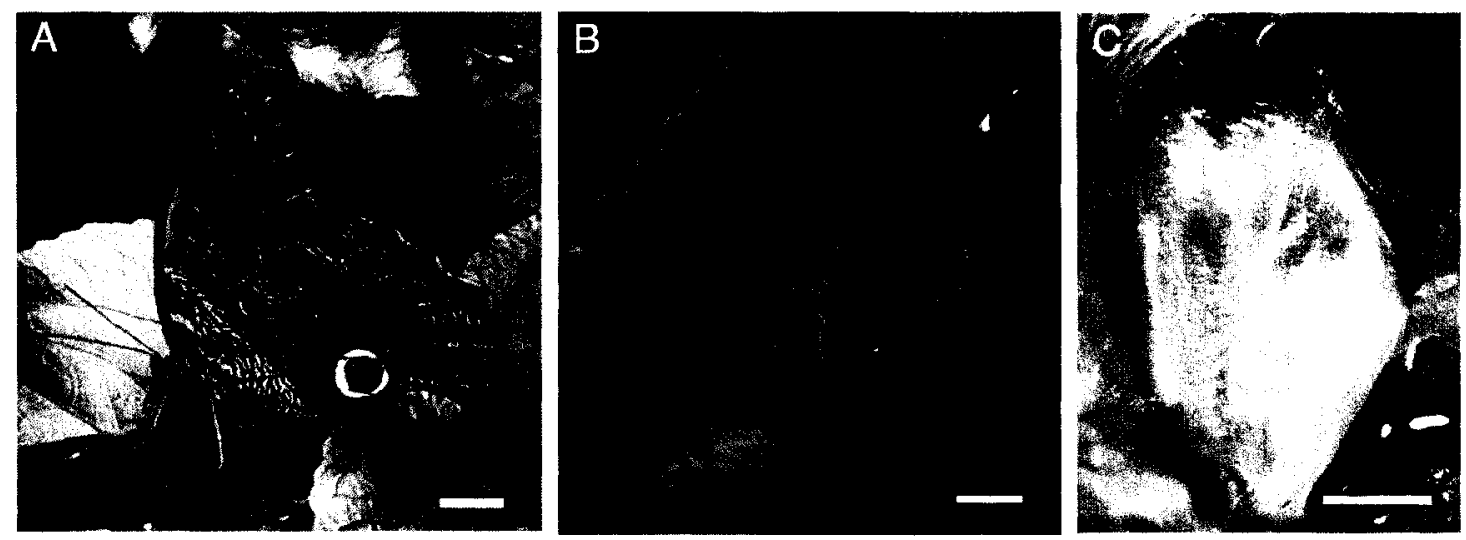

Figure 3.2. Location and external morphology of the Vogel's organ (VO) on the butterfly Caligo eurilochus. (A) The natural resting position of $C$. eurilochus, with the VO exposed on the forewing. Scale bar $=1 \mathrm{~cm}$. (B) Close-up of VO, scale bar $=500 \mu \mathrm{m}$. (C) Close-up of VO, scale bar $=500 \mu \mathrm{m}$. 

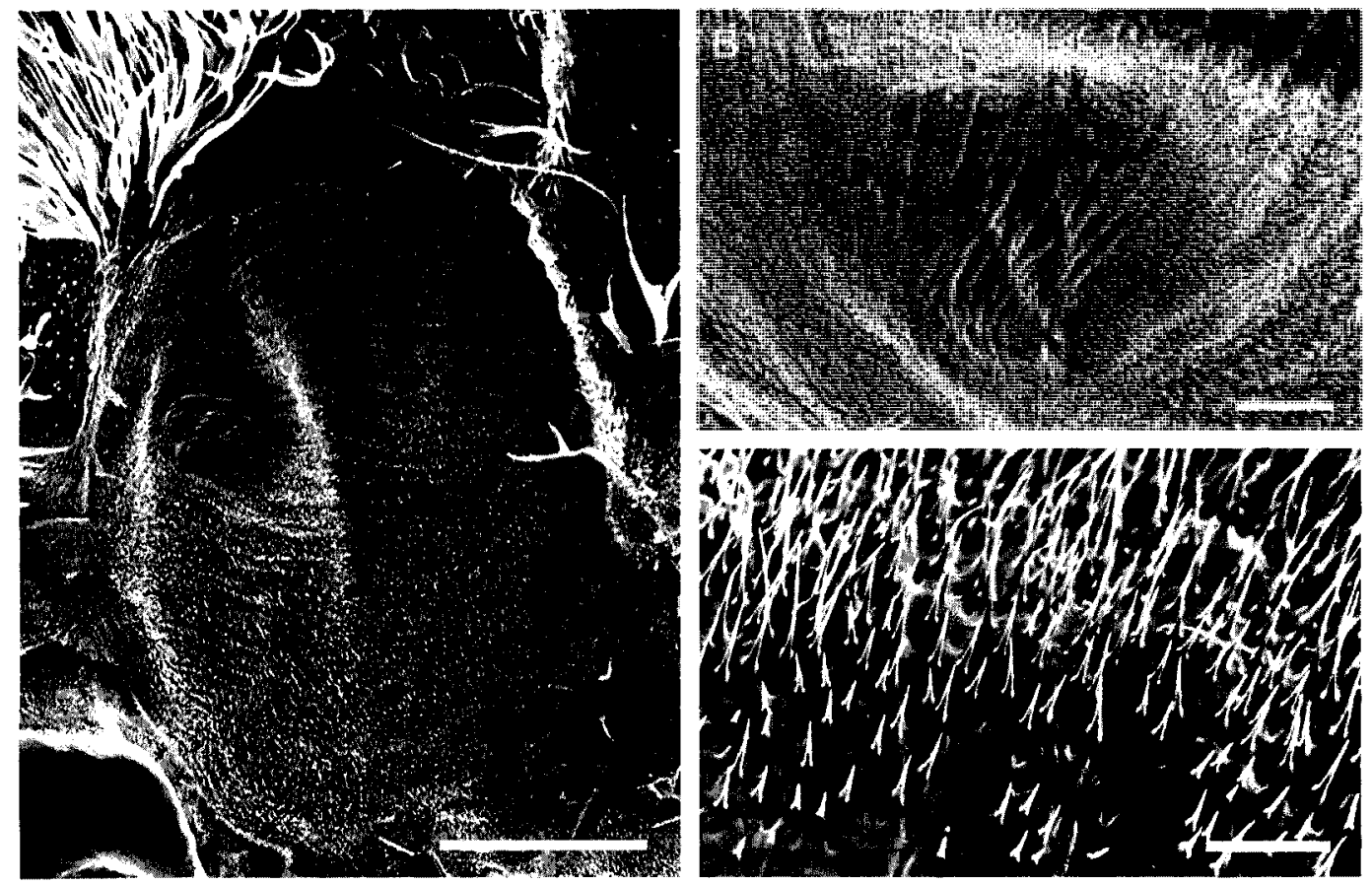

Figure 3.3. Scanning electron micrographs of the Caligo eurilochus Vogel's organ. (A) Whole view of the left tympanal membrane (anterior on the left). Scale bar $=500 \mu \mathrm{m}$. (B) Close-up of the dark spot (see Fig. 2C) near the distal end of the anterior side of the membrane, scale bar $=$ $100 \mu \mathrm{m}$. (C) Close-up of the scales around the dark spot, showing how the microtrichia diminishing towards the center of the spot. Scale bar $=200 \mu \mathrm{m}$. 
that are approximately $10-15 \mu \mathrm{m}$ in length except on the dark spot, where the microtrichia shorten, then disappear leaving the membrane flat (Fig. 3.3B, C).

\subsubsection{Neurophysiology}

The nerve branches extending from the main wing nerve IIN1c appear to be homologous to those described in other nymphalid butterflies including the three main branches, N.I, N.II, and N.III (M. peleides in Lane et al., 2008; P. aegeria in Mahony, 2006; and H. feronia in Yack et al., 2000). As such, the two branches N.II and N.III that have been found to innervate the ear in these nymphalid butterflies were focused on.

N.II and N.III responded to pure tone acoustic stimuli between 0.4 and $25 \mathrm{kHz}$, with the most consistent and sensitive response between 0.7 and $5 \mathrm{kHz}$. The neural response in all recordings consisted of compound action potentials and was tonic for all stimulus durations (Fig. 3.4). At just above threshold, latencies ranged between 7 and 9 $\mathrm{ms}$, indicating that the neural response was sensory.

The hearing range of seven $C$. eurilochus specimens was tested by performing extracellular nerve recordings to generate nine audiograms (Fig. 3.5). These preliminary studies did not find any differences in the response between the sexes (six male audiograms and three female audiograms). While this is not sufficient replication to say conclusively whether sexual dimorphism with respect to hearing exists, no difference in hearing sensitivity was found. There was also no difference in the response of the N.II and N.III branches, however greater replication is also required to state this conclusively. The best frequency was $3.0 \mathrm{kHz}$ with an average threshold of $74 \mathrm{~dB}$, with a best 


\section{A) $2 \mathrm{kHz}$}

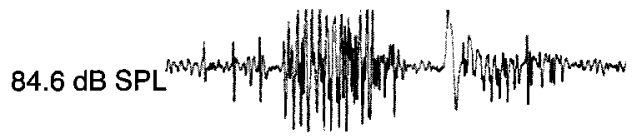

$75.8 \mathrm{~dB}$ SPL
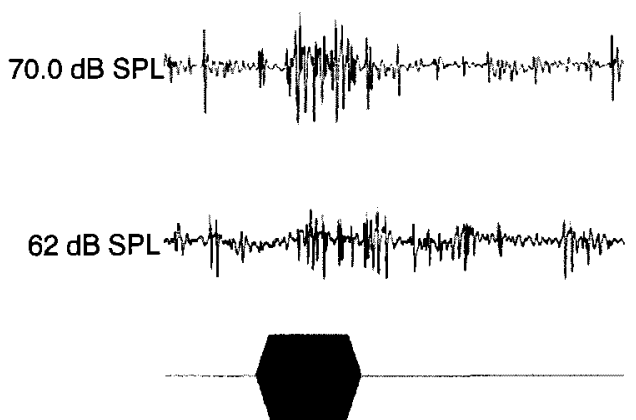

B) $6 \mathrm{kHz}$

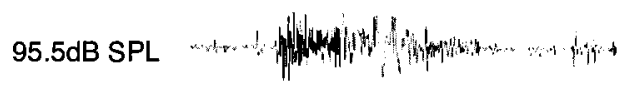

$85.5 \mathrm{~dB}$ SPL

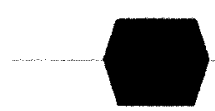

\section{C) $21 \mathrm{kHz}$}

103.4 dB SPL

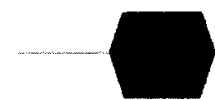

Figure 3.4. Representative neural traces recorded from the innervating nerve branches in the Caligo eurilochus Vogel's organ. (A) Intensity-response relationships recorded from the N.III branch to a $2 \mathrm{kHz} 30 \mathrm{~ms}$ shaped pulse played at 1 pulse per second. (B) Intensity response relationship recorded from N.III to a $6 \mathrm{kHz}$ pure tone. (C) Neural response recorded from N.II and N.III to a $21 \mathrm{kHz}$ pure tone. 

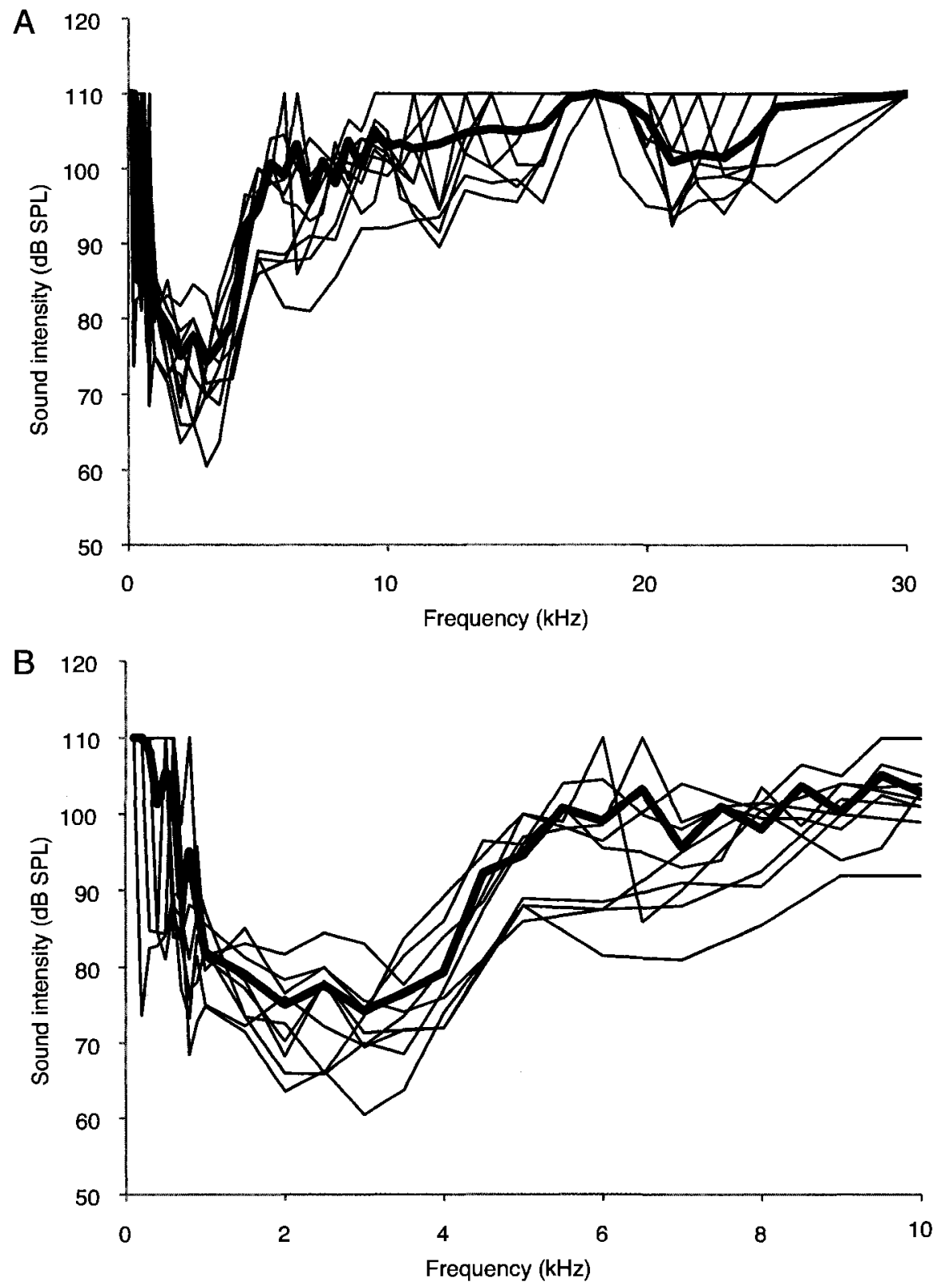

Figure 3.5. Audiograms for Caligo eurilochus. (A) 1-30 kHz. (B) Close-up, 1-10 $\mathrm{kHz}$. The best frequency was $3 \mathrm{kHz}$ with an average threshold of $74 \mathrm{~dB}$ SPL. Best individual threshold at $3 \mathrm{kHz}$ was $60.5 \mathrm{~dB}$ SPL. 
individual threshold of $60.5 \mathrm{~dB}$ SPL. While thresholds were obtained for frequencies above $5 \mathrm{kHz}$, these responses were relatively inconsistent, and had average thresholds above $100 \mathrm{~dB}$ SPL. The audiograms show consistent threshold responses below $100 \mathrm{~dB}$ SPL for frequencies between 0.7 and $5 \mathrm{kHz}$.

\subsubsection{Laser vibrometry}

The VO of ten C. eurilochus were scanned using Doppler laser vibrometry to test the vibrational response to sound stimuli between $100 \mathrm{~Hz}$ to $30 \mathrm{kHz}$. While the membrane responded to this frequency range, its vibration was most coherent in response to frequencies between 1 and $20 \mathrm{kHz}$. The $C$. eurilochus membrane had a single mode of vibration, with a mechanical response similar to a simple harmonic oscillator (Fig. 3.6). The focus of the vibration cycle occurred at a point just proximal of the center of the membrane. This point on the membrane exhibited the largest displacement gain at 2.5 $\mathrm{kHz}$, with a displacement of approximately $550 \mathrm{~nm} / \mathrm{Pa}$ (Fig. 3.7). Between $1-5 \mathrm{kHz}$, the membrane exhibited an amplitude response of over $100 \mathrm{~nm} / \mathrm{Pa}$. Above $5 \mathrm{kHz}$, the membrane displacement gain decreased quickly to approximately $20 \mathrm{~nm} / \mathrm{Pa}$. In contrast, the shape of the vibration remained the same for all coherent frequencies, as shown in Fig. 3.8.

\subsection{Discussion}

We predicted that if the function of VO in diurnal, mute butterflies is to detect avian predators, then the $C$. eurilochus VO would be a degenerate ear. If $C$. eurilochus 

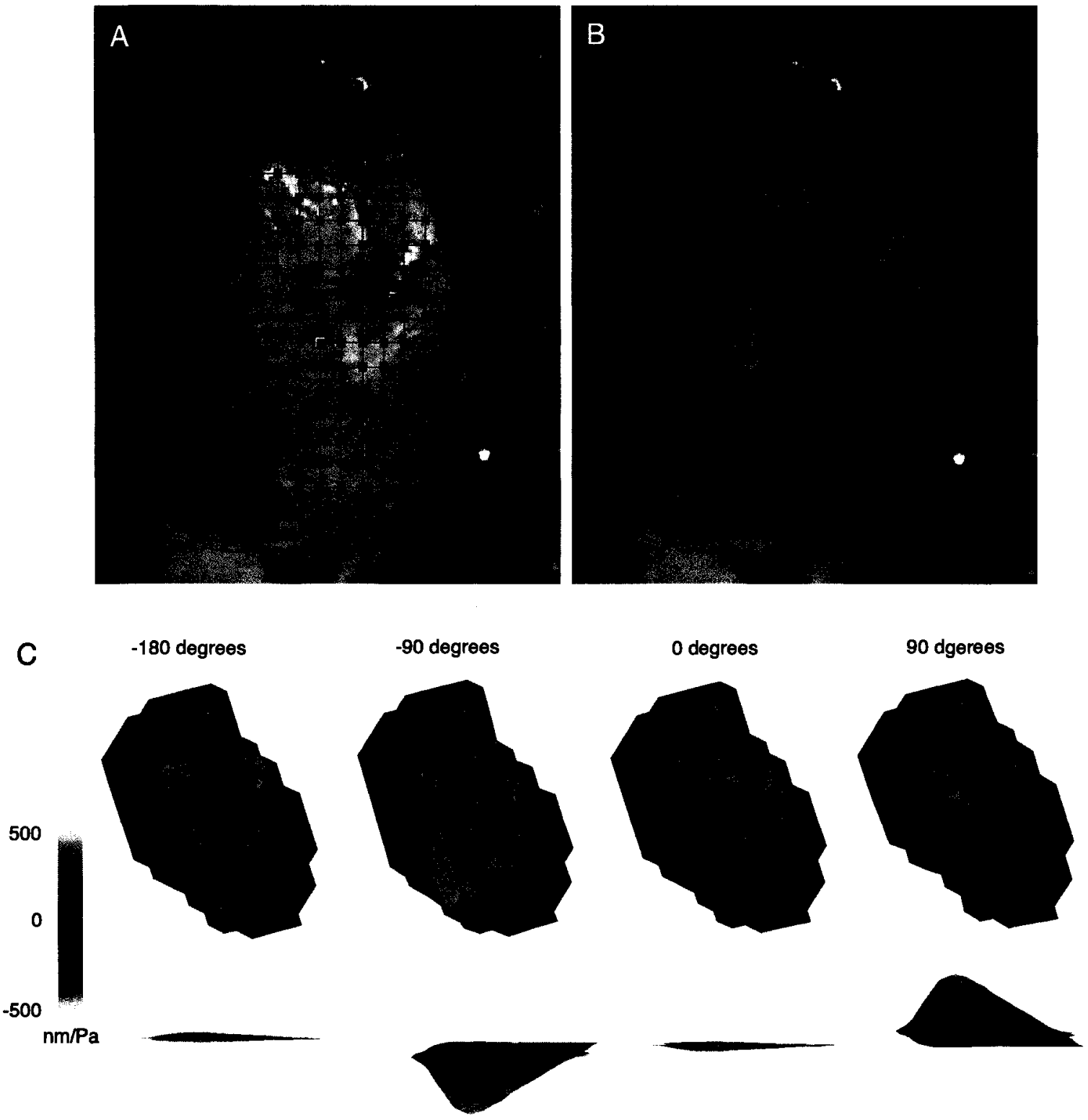

Figure 3.6. The vibrational response of the Caligo eurilochus tympanal membrane to a $2.4 \mathrm{kHz}$ tone. (A-B) Orientation image of the tympanal membrane displaying the scan region and points included in the area scan. (C) Tympanal displacement in response to sound frequencies at $2.4 \mathrm{kHz}$. Each set is shown at four different phases throughout the oscillation cycle. The profile is shown from both a top view and a side view. 


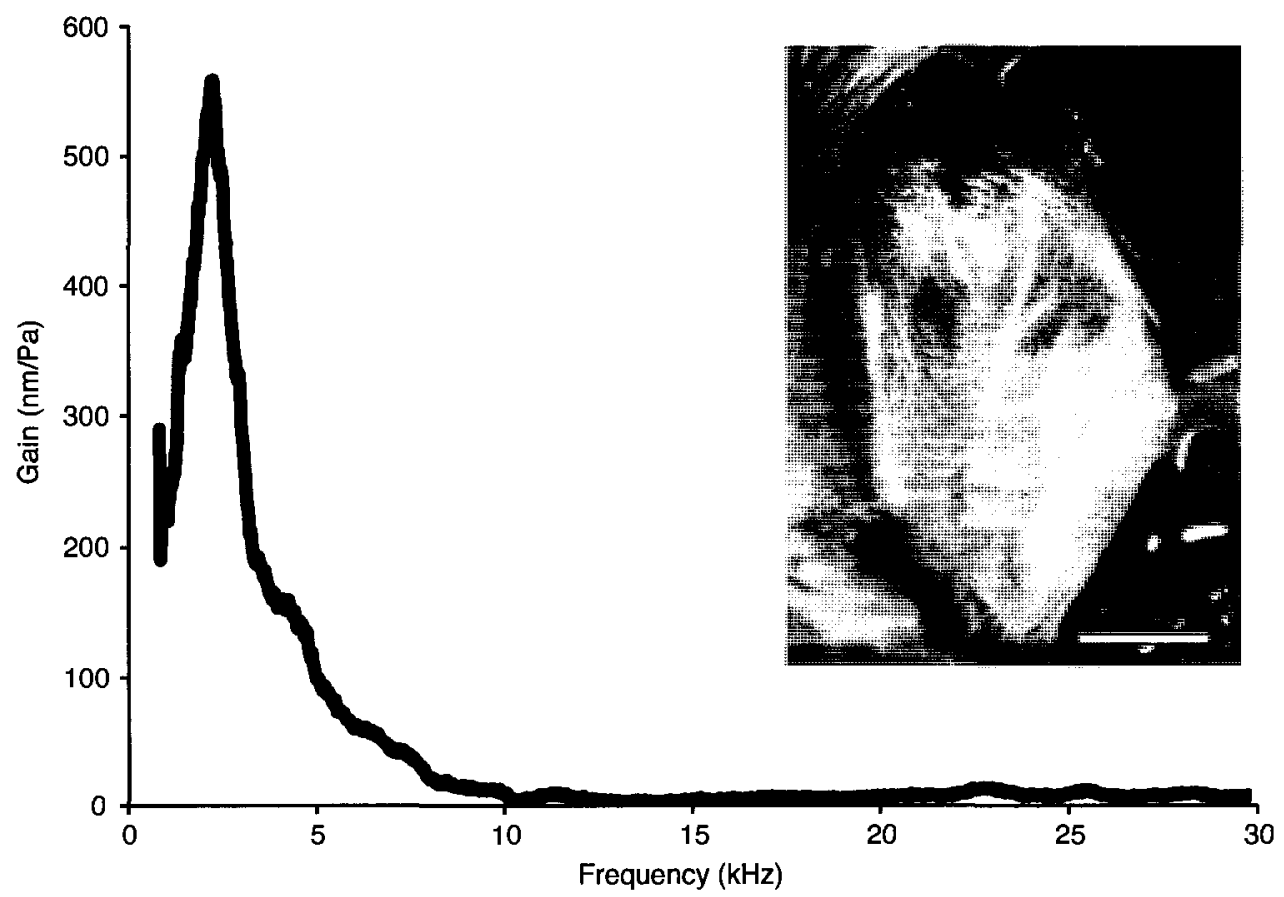

Figure 3.7. The amplitude gain response of the Caligo eurilochus membrane to sound frequencies between $1-30 \mathrm{kHz}$ sampled from the middle of the membrane, as shown on the inset image of the $C$. eurilochus Vogel's organ with an asterisk (scale bar $=500 \mu \mathrm{m}$ ). This point represents the focus of the membrane vibration ('node'). 

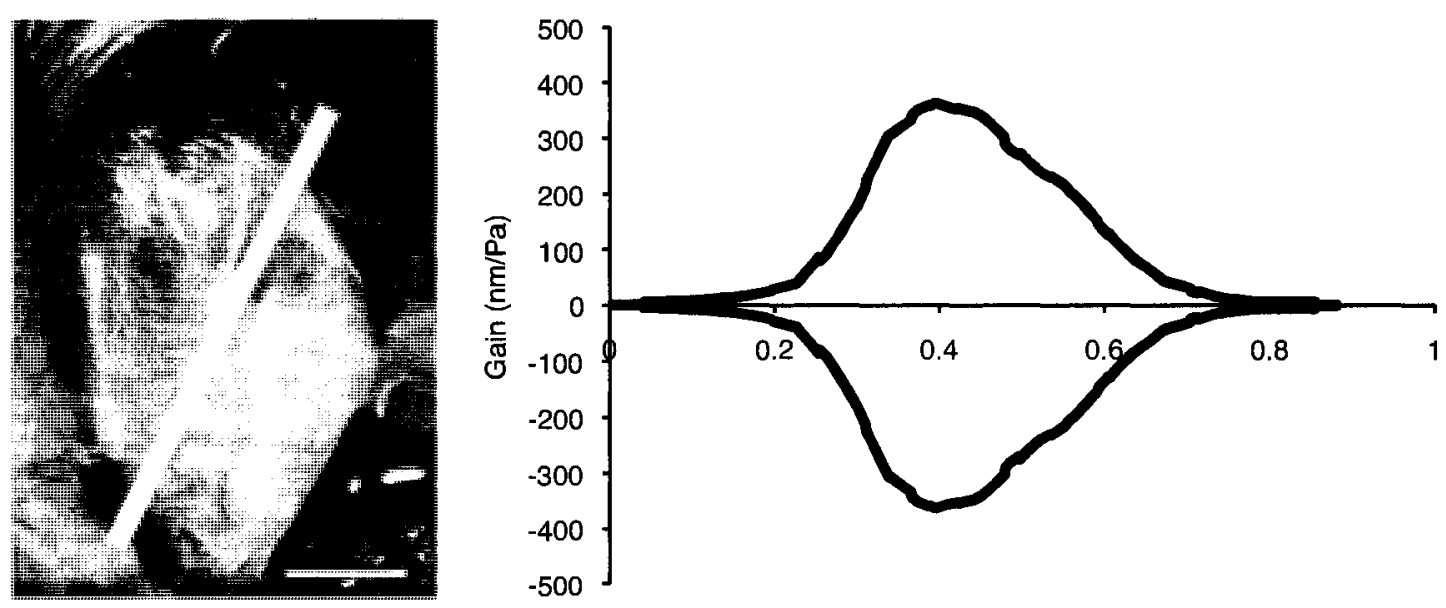

Figure 3.8. The deflection envelope of the amplitude gain response of the tympanal membrane in Caligo eurilochus. The transect measured is showed on the light micrograph of the Vogel's organ with a white line, scale bar $=500 \mu \mathrm{m}$. 
had moved into the night as has been suggested (Penz and DeVries, 2002; Fredericksen and Warrant, 2008), it would be predicted that the loss of significant predation pressure from birds would relieve the need for a VO. A loss of hearing in response to a reduction in selective pressure has been documented in other insects. Moths removed from bat predation show a loss of high frequency hearing, such as in diurnal dioptine moths (Fullard et al., 1997; Fullard et al., 2000), and in moths that are endemic to bat-free habitats (Fullard, 1994). Some diurnal moths have been shown to have functioning high frequency ears, however these species have been shown to either (1) still be active for a portion of their 24h cycle at night (e.g. Caenurgina erechtea, Fullard and Dawson (1999); Fullard et al. (2000)), or (2) produce high frequency sound thought to function in conspecific communication (arctiid moths Cycnia tenera and Ctenucha virginica, Fullard and Dawson 1999; reviewed in Conner, 1999). Sexual dimorphism in auditory capability has also been attributed to different selection pressures experienced by the sexes in some insects. In the gypsy moth Lymantria dispar, females are normally flightless and therefore less susceptible to predation by aerial hawking bats (Cardone and Fullard, 1988). Correspondingly, hearing in females is significantly less sensitive than males in the ultrasonic range (Cardone and Fullard, 1988). Male Australian katydids (Kawanaohila nartee, Orthoptera, Ensifera) have ears that are 10dB less sensitive than females, which is thought to be the result of a reduction in male-male competition (Bailey and Romer, 1991; Mason and Bailey, 1998). Flightless female preying mantises have reduced auditory sensitivities, which corresponds to reduced exposure to bat predation (Yager, 1990). 
Ultimately, the presence of a degenerate ear would support the avian hypothesis. Therefore, is the $C$. eurilochus ear a degenerate form of the M. peleides VO? Caligo eurilochus was found to have a low-frequency ear, detecting sound stimuli between 0.4 and $23 \mathrm{kHz}$, with the greatest sensitivity between $1-5 \mathrm{kHz}$. This suggests that M. peleides and $C$. eurilochus may be listening to the same natural sound stimuli, namely the sounds produced by avian predators. Despite sharing the same hearing range, $C$. eurilochus does not have as sensitive hearing as $M$. peleides. At the best frequency of $3 \mathrm{kHz}$, the average threshold was $74 \mathrm{~dB}$ SPL, as compared to an average threshold of $65 \mathrm{~dB}$ SPL at its best frequency of $2-4 \mathrm{kHz}$ in M. peleides (Fig. 3.9). This is comparable to other insect degenerate ears, such as in the dioptine moths, which possess a higher median threshold of approximately $10 \mathrm{~dB}$ SPL compared to other nocturnal moths (Fullard et al., 1997). The sensitive range in C. eurilochus is much shorter as well, with a large fall in sensitivity above $5 \mathrm{kHz}$ (Fig. 3.9).

The vibrational response of the tympanal membrane also differs between the two species. Morpho peleides was found to have a vibrational response with two frequency dependent modes (Chapter 2). These two vibrational modes corresponded to the attachment points of the chordotonal organs in the M. peleides VO, suggesting that the $M$. peleides may be detecting differences in frequencies. The $C$. eurilochus membrane has only one mode of vibration, and simply responds to an incoming sound stimulus between 0.5 and $20 \mathrm{kHz}$ as a simple harmonic oscillator (Fig. 3.6). While the presence and location of chordotonal organs is not known in this species, it is unlikely that it would be able to distinguish between frequencies, making it an 'all or nothing' ear as observed in 


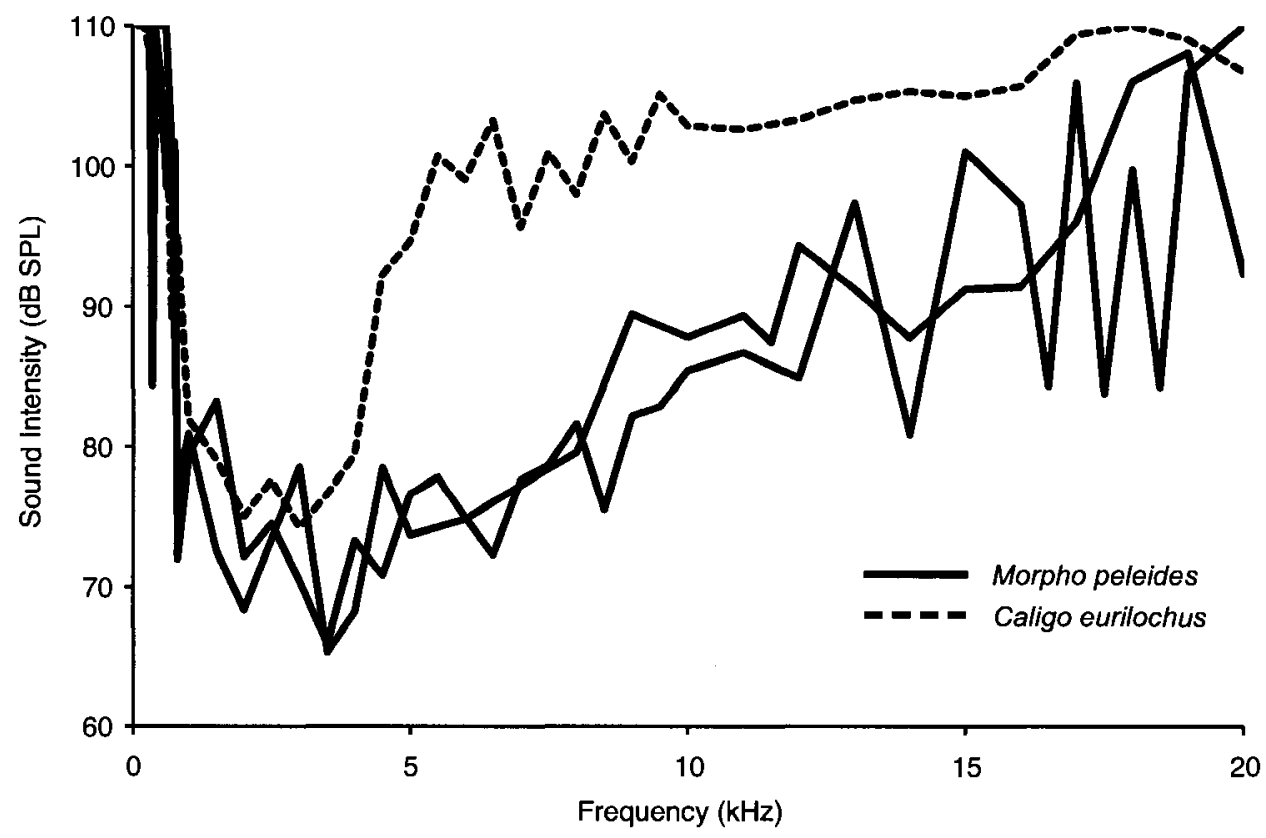

Figure 3.9. Comparison of the average auditory thresholds for Caligo eurilochus and Morpho peleides. The two lines for $M$. peleides represent individual averages recorded from N.II and N.III respectively, while the $C$. eurilochus line represents the combined response of N.II and N.III. 
moths. Overall, though $C$. eurilochus listens to the same frequencies as M. peleides, it appears to be a simpler, less sensitive ear.

As a degenerate ear, what is the significance of the $C$. eurilochus VO in terms of the avian hypothesis? It is hypothesized that the low frequency ears observed in $M$. peleides functions to detect the sounds of predatory birds. If the ancestor of $M$. peleides and $C$. eurilochus had a functioning, low-frequency ear, as the Brassolini tribe moved into the night, the selection pressure of avian predators would have diminished. If the function of the low frequency ear was to detect these predators, it is expected that it would degenerate with the loss of the selection pressure, ultimately supporting the avian hypothesis.

While a degenerate ear in C. eurilochus supports the avian hypothesis, it has not been tested explicitly here. Further research to test the avian hypothesis will include playback studies of bird flight sounds to determine whether this mediates a behavioural response. Observation of the two species in their natural habitat will also be essential to confirm predation in nature. 


\section{Chapter 4.}

\section{General Discussion}

Until recently, hearing in butterflies has received little experimental attention. A functional sense of hearing in butterflies is now being shown to be widespread based on morphological and physiological evidence. High frequency bat detecting ears, much like those found in the moths, have been described (e.g. the hedylid M. heliconaria (Yack and Fullard, 2000), and the nymphalid M. maculata (Rydell et al., 2003)), as well as low frequency ears to which a function remains untested (except in the conspecific communicator $H$. feronia, Yack et al. (2000)). This study focused on the low frequency hearing in two tropical butterflies, Morpho peleides and Caligo eurilochus, to test both the proximate and ultimate functions of Vogel's organ (VO) in these representative species.

Having previously been described morphologically and neurophysiologically as a working hearing organ (Lane et al., 2008), M. peleides provided an excellent opportunity to study the proximate mechanisms of hearing, where specific questions regarding the functional significance of its membrane structure could be addressed. The heterogeneous membrane, composed of the bulbous inner membrane and flat outer membrane, suggested that it would not exhibit a simple vibration response. This was confirmed using laser Doppler vibrometry studies, which showed that the membrane had a frequency dependent vibrational response. Coincidentally, the locations at which the three chordotonal organs were associated with the membrane matched the centers of the two 
modes of vibration. In other insects with a similarly paired membrane response and sensory organ attachment sites, this has resulted in the insect being able to discriminate between frequencies (e.g. locust, cicada). Further research is required to determine whether the VO morphology in M. peleides results in the animal being able to distinguish different frequencies. This can be approached in two ways. One way would be to perform intracellular recordings of sensory afferents in the different chordotonal organs that respond to different frequencies as well as interneurons to tease out whether individual cells in the chordotonal organs are tuned to specific frequencies. Second, the behavioural response of $M$. peleides to relevant biological stimuli could show whether the animal responds to different stimuli with different responses. It has been hypothesized that diurnal, non-sound producing butterflies may use their low-frequency ears to detect their avian predators, including their calls (Ribaric and Gogala, 1996) or their flight sounds (Lane et al., 2008). It could be important for the butterfly to detect whether its predator is simply in the vicinity (based on their calls), or in the process of approaching to attack (based on their flight sounds). Whether or not M. peleides is able to discriminate between frequencies, this line of research is crucial in determining the function of hearing in this and other diurnal, non-sound producing butterflies.

Another way to test the ultimate function of hearing in butterflies is to look at a species that either has no hearing, or perhaps a degenerate form. Caligo eurilochus provided a platform to indirectly test the avian hypothesis through comparison with its relative M. peleides. It was found that while $C$. eurilochus has a functional VO, it is a relatively insensitive one. This may in part be due to the 'simple' vibrational response of its tympanal membrane to low frequency stimuli within its hearing range. Caligo 
eurilochus and M. peleides are in the tribes Brassolini and Morphini, respectively, and would have shared a common ancestor. Since both species have ears, it can be hypothesized that this shared ancestor had either the precursor to or a fully functional VO. When the Brassolini tribe broke away from the Morphini (Penz and DeVries, 2002) and shifted to a crepuscular lifestyle, the selective pressure of insectivorous birds would have been alleviated. In response, without any need for a hearing organ to detect avian predators, the hearing organ would degenerate. The evidence provided for the $C$. eurilochus hearing organ certainly suggests that its insensitivity and lack of complexity may indeed be the result of degeneration. This in turn supports the avian hypothesis, for the main difference between C. eurilochus and M. peleides is their temporal habitats that coincides with a shift in predation. This preliminary description of the C. eurilochus VO provides an opportunity to further test the avian hypothesis and the ultimate function of VO in diurnal, non-sound producing butterflies. Further research should focus on a more comprehensive description of the VO, including histological studies to show the presence and location of sensory chordotonal organs and neurophysiological analysis of the separate branches. A morphological survey of species from both the Brassolini and Morphini tribes is also necessary to detect how widespread VO is in these two groups, as well as a comparison of VO complexity with natural histories to further support the avian hypothesis.

This study sets a groundwork for further research into butterfly hearing in general. By understanding both how and why these organs detect sound stimuli, we are provided with insight into the evolution of a novel sensory system in a previously overlooked group of insects. 


\section{References}

Ackery, P.R., de Jong, R. and Vane-Wright, R.I. (1999). The Butterflies: Hedyloidea, Hesperoidea and Papilionoidea. In Handbook of Zoology. Bol. 4. Arthropoda: Insecta. Lepidoptera, Moths and Butterflies. Vol. 1. Evolution, Systematics, and Biogeography. (Ed. N.P. Kristensen), pp. 263-300. Berlin: Walter de Gruyter.

Bailey, W.J., and Romer, H. (1991). Sexual differences in auditory sensitivity: mismatch of hearing threshold and call frequency in tettigoniid (Orthoptera, Tettigoniidae: Zaprochilinae). J. Comp. Physiol. A. 169, 349-353.

Bowers, M.D., Brown, I.L., and Wheye, D. (1985). Bird predation as a selective agent in a butterfly population. Evolution, 39, 93-103.

Brower, A.V.Z. (2000). Phylogenetic relationships among the Nymphalidae (Lepidoptera) inferred from partial sequences of the wingless gene. Phil. R. Soc. Lond. B. 267, 1201-1211.

Cardone, B., and Fullard, J.H. (1988). Auditory characteristics and sexual dimorphism in the gypsy moth. Physiol. Entomol. 13, 9-14.

Chai, P. (1996). Butterfly visual characteristics and ontogeny of responses to butterflies by a specialized tropical bird. Biol. J. Linnean Soc. 59, 37-67.

Chai, P., and Srygley, R.B. (1990). Predation and the Flight, Morphology, and Temperature of Neotropical Rain-Forest Butterflies. Am. Nat. 135, 748-765.

DeVries, P. J. (Ed.). (1987). The Butterflies of Costa Rica and their Natural History. Vol I: Papilionoidea, Pieridae, Nymphalidae. University of Chicago Press.

Frederiksen, R., and Warrant, E.J. (2008). Visual sensitivity in the crepuscular owl butterfly Caligo memnon and the diurnal blue morpho Morpho peleides: a clue to explain the evolution of nocturnal apposition eyes? J. Exp. Biol. 211, 844-851.

Freitas, A.V.L., and Brown, K.S. (2004). Phylogeny of the Nymphalidae (Lepidoptera). Syst. Biol. 53, 363-383.

Freitas, A.V.L., Benson, W.W., Marini-Filho, O.J., and de Carvalho, R.M. (1997). Territoriality by the dawn's early light: the Neotropical owl butterfly Caligo idomenaeus (Nymphalidae: Brassolinae). J. Res. Lepidoptera. 54, 14-20.

Fonseca, P.J., Munch, D., and Hennig, R.M. (2000). How cicadas interpret acoustic signals. Nature 405, 297-298.

Fullard, J.H. (1994). Auditory changes in noctuoid moths endemic to a bat-free habitat. J. Evol. Biol. 7, 435-445. 
Fullard, J.H., and Dawson, J.W. (1999). Why do diurnal moths have ears? Naturwissenschaften, 86, 276-279.

Fullard, J.H., Dawson, J.W., Otero, L.D., and Surlykke, A. (1997). Bat-deafness in day-flying moths (Lepidoptera Notodontidae, Dioptinae). J. Comp. Physiol. A. $181,477-483$.

Fullard, J.H., Otero, L.D., Orellana, A., and Surlykke, A. (2000). Auditory Sensitivity and Diel Flight Activity In Neotropical Lepidoptera. Ann. Entomol. Soc. Am. 93, 956-965.

Glauert, A.M. (Ed.). (1975). Fixation, Dehydration and Embedding of Biological Specimens. Amsterdam: North Holland Publishing Company, Amsterdam.

Gray, E.G. (1960). The fine structure of the insect ear. Phil. Trans. R. Soc. Lond. B. 243, 75-94.

Hallberg, E., and Poppy, G. (2003) Exocrine glands: Chemical communication and chemical defense. In Handbook of zoology/handbuch der zoologie. Lepidoptera, moths and butterflies, morphology and physiology, vol. 2. (Ed. Kristensen, P.) pp. 361-375. Berlin: Walter de Gruyter.

Hennig, R.M., Franz, A., and Stumpner, A. (2004). Processing of Auditory Information in Insects. Microscopy Res. Tech. 63, 351-374.

Kristensen, N.P., and Skalski, A.W. (1999). Phylogeny and Palaeontology. In Handbook of Zoology. Bol. 4. Arthropoda: Insecta. Lepidoptera, Moths and Butterflies. Vol. 1. Evolution, Systematics, and Biogeography. (Ed. N.P. Kristensen), pp. 7-25. Berlin: Walter de Gruyter.

King, J.D. (2007). Butterfly Hearing: A Comparative Study. B.Sc. Honours thesis, Carleton University, Ottawa, Canada.

Lane, K.A., Lucas, K.M. and Yack, J.E. (2008). Hearing in a Diurnal, Mute Butterfly, Morpho peleides (Papilionoidea, Nymphalidae). J. Comp. Neurol. 508, 677-686.

LeCerf, F. (1926). Contribution à l'étude des organs sensoriels des Lépidoptères. Encyclop. Ent. 3: 133-146.

Mahony, S. (2006). Hearing in the speckled wood butterfly, Pararge aegeria (Nymphalidae: Satyrinae). M.Sc. thesis, Carleton University, Ottawa, Canada.

Marden, J.H., and Chai, P. (1991). Aerial Predation and Butterfly Design: How Palatability, Mimicry, and the Need for Evasive Flight Constrain Mass Allocation. Am. Nat. 138, 15-36. 
Mason, A.C., and Bailey, W.J. (1998). Ultrasound hearing and male-male communication in Australian katydids (Tettigoniidae: Zaprochilinae) with sexually dimorphic ears. Physiol. Entomol. 23, 139-149.

Michelsen, A. (1971a). The Physiology of the Locust Ear. II. Frequency Discrimination Based upon Resonances in the Tympanum. Z. vergl. Physiol. 71, 63-101.

Michelsen, A. (1971b). The Physiology of the Locust Ear. I. Frequency sensitivity of Single Cells in the Isolated Ear. Z. vergl. Physiol. 71, 49-62.

Minet, J., and Surlykke, A. (2003) Sound producing and auditory organs. In Handbook of zoology/hanbuch der zoologie. Lepidoptera, moths and butterflies, morphology and physiology, vol. 2. (Ed. Kristensen, P.), pp. 289-323. Berlin: Walter de Gruyter.

Novacek, M. J. (1985). Evidence for echolocation in the oldest known bats. Nature, 315, 140-141.

Otero, L.D. (1990). Estudio de algunos caracteres para su uso en la clasificación de Eurytelinae (Lepidoptera: Nymphalidae). Bol. Ent. Venez. 5: 123-138.

Pena, C., Wahlberg, N. Weingartner, E., Kodandaramaiah, U., Nylin, S., Freitas A.V.L., and Brower, A.V.Z. (2006). Higher level phylogeny of Satyrinae butterflies (Lepidoptera: Nymphalidae) based on DNA sequence data. Mol. Phylo. Evol. 40, 29-49.

Penz, C.M., and DeVries, P.J. (2002). Phylogenetic Analysis of Morpho Butterflies (Nymphalidae, Morphinae): Implications for Classification and Natural History. Am. Mus. Nov. 3374, pp. 17.

Ribaric, D. and Gogala, M. (1996). Acoustic behaviour of some butterfly species of the genus Erebia (Lepidoptera: Satryidae). Acta. Ent. Slov. 4: 5-12.

Rydell, J., Kaerma, S., Hedelin, H., and Skals, H. (2003). Evasive response to ultrasound by the crepuscular butterfly Manataria maculata. Naturwissenschaften, 90: 80-83.

Scoble, M.J. (1986). The structure and affinities of the Hedyloidea: a new concept of the butterflies. Bull. Brit. Mus. Nat. Hist. 53, 251-286.

Scoble, M.J., and Aiello, A. (1990). Moth-like butterflies (Hedylidae: Lepidoptera): a summary, with comments on the egg. J. Nat. Hist. 24, 159-164.

Srygley, R.B. (1994). Shivering and its cost during reproductive behaviour in Neotropical owl butterflies, Caligo and Opsiphanes (Nymphalidae: Brassolinae). Anim. Behav. 47, 23-32. 
Sueur, J., Windmill, J.F.C., and Robert, D. (2006). Tuning the drum: the mechanical basis for frequency discrimination in a Mediterranean cicada. J. Exp. Biol. 209, 4115-4128.

Vogel, R. (1912). Über die Chordotonalorgane in der Wurzel der Schmetterlingsflügel. Z. Wiss. Zool. 100, 210-244.

Wahlberg, N., and Brower, A.V.Z. 2006. Satyrinae Boisduval 1833 "Satyridae" of authors. Version 09 November 2006 (under construction). Available online at http://tolweb.org/Satyrinae/12189/2006.11.09 in The Tree of Life Web Project, http://tolweb.org/.

Wahlberg, N., Weingartner E., and Nylin, S. (2003). Towards a better understanding of the higher systematics of Nymphalidae (Lepidoptera: Papilionoidea). Mol. Phylo. Evol. 28, 473-484.

Wahlberg, M., Braby, M.F., Brower, A.V.Z., de Jong, R., Lee, M.-M., Nylin, S., Pierce, N.E., Sperling, F.A.H., Vila, R., Warren, A.D., and Zakharov, E. (2005). Synergistic effects of combining morphological and molecular data in resolving the phylogeny of butterflies and skippers. Proc. R. Soc. Lond. B. 272, 1577-1586.

Warrant, E., Kelber, A. and Kristensen, N.P. 2003. Visual organs. In Handbook of zoology/hanbuch der zoologie. Lepidoptera, moths and butterflies, morphology and physiology, vol. 2. (Ed. Kristensen, P.), pp. 325-359. Berlin: Walter de Gruyter.

Windmill, J.F.C., Gopfert, M.C., and Robert, D. (2005). Tympanal travelling waves in migratory locusts. J. Exp. Biol. 208, 157-168.

Windmill, J.F.C., Jackson, J.C., Tuck, E.J., and Robert, D. (2006). Keeping up with Bats: Dynamic Auditory Tuning in a Moth. Curr. Biol. 16, 2418-2423.

Windmill, J.F.C., Fullard, J.H., and Robert, D. (2007). Mechanics of a 'simple' ear: tympanal vibrations in noctuid moths. J. Exp. Biol. 210, 2637-2648.

Yack, J.E. (2004). The structure and function of auditory chordotonal organs in insects. Microscopy Res. Tech. 63, 315-337.

Yack, J.E., and Fullard, J.H. (1993). What is an insect ear? Ann. Ent. Soc. Am. 86(6), 677-682.

Yack, J.E., and Fullard, J.H. (2000). Ultrasonic hearing in nocturnal butterflies. Nature 403, $265-266$.

Yack, J.E., Hoy, R.R. (2004). Hearing. In: Encyclopedia of Insects (Eds. V.H. Resh \& R. Cardé). Academic Press, San Diego, CA. 
Yack, J.E., Otero, L.D., Dawson, J.W., Surlykke, A., and Fullard, J.H. (2000). Sound production and hearing in the blue cracker butterfly Hamadryas feronia (Lepidoptera, Nymphalidae) from Venezuela. J. Exp. Biol. 203, 3689-3702.

Yack, J.E., Kalko, E., and Surlykke, A. (2007). Neuroethology of ultrasonic hearing in noctural butterflies (Hedyloidea). J. Comp. Physiol. A. in press.

Yager, D.D. (1990). Sexual dimorphism of auditory function and structure in preying mantises (Mantodea; Dictyoptera). J. Zool., Lond. 221, 517-537.

Yager, D. (1999) Structure, development, and evolution of insect auditory systems. Microscopy Res. Tech. 47, 380-400. 